AperTO - Archivio Istituzionale Open Access dell'Università di Torino

\title{
A Trade-Off Theory of Ownership and Capital Structure
}

\section{This is the author's manuscript}

Original Citation:

Availability:

This version is available http://hdl.handle.net/2318/1694879

since 2019-12-30T09:30:10Z

Published version:

DOI:10.1016/j.jfineco.2018.09.001

Terms of use:

Open Access

Anyone can freely access the full text of works made available as "Open Access". Works made available under a Creative Commons license can be used according to the terms and conditions of said license. Use of all other works requires consent of the right holder (author or publisher) if not exempted from copyright protection by the applicable law. 


\title{
A Trade-off Theory of Ownership and Capital Structure
}

\author{
Giovanna Nicodano ${ }^{\mathrm{a}}$, Luca Regis ${ }^{\mathrm{b}}$ \\ ${ }^{a}$ Corresponding Author. Collegio Carlo Alberto and ESOMAS, Università di Torino; and ECGI; \\ postal address: Corso Unione Sovietica 218/bis, 10100 Torino, Italy; e-mail:giovanna.nicodano@unito.it. \\ ${ }^{b}$ University of Siena, Department of Economics and Statistics; \\ postal address: Piazza San Francesco 7/8, 53100 Siena, Italy; e-mail: luca.regis@unisi.it.
}

\begin{abstract}
This paper determines the optimal ownership share held by a unit into a second unit, when both face a tax-bankruptcy trade-off. Full ownership is optimal when the first unit has positive debt, because dividends help avoid its default. Positive debt is, in turn, optimal when its corporate tax rate exceeds a threshold; and/or Thin Capitalization Rules place an upper limit on the debt level in the second unit, and/or the Volcker Rule bans bailout transfers to the second unit. Full ownership is no longer optimal only if there is a tax on intercorporate dividend. This theory rationalizes observations on multinationals, financial conglomerates and family groups.

Keywords: ownership, leverage, taxes, Thin Capitalization, groups, multinationals. JEL classification: G32, H32.
\end{abstract}

This version: November 21, 2017 


\section{Introduction}

Shareholders in control of multiple units may directly own equity in each of them. This gives rise to a horizontal group, an organization that family firms sometimes adopt (Masulis et al., 2011). Groups are instead hierarchical when the controlling investors indirectly own the shares of one unit through another unit. Outside investors may buy minority stakes in affiliates of a hierarchical group, giving rise to pyramidal groups (La Porta et al., 1999), but this is not the rule. For instance, parent companies in multinational groups often fully own their subsidiaries (Lewellen and Robinson, 2013). One trait of units connected through common control is their reliance on debt financing (Huizinga et al., 2008; Kolasinski, 2009; Masulis, 2011). Sometimes the parent unit raises most of the debt, while in other instances other units - such as the Leveraged Buy Out (LBO) targets - bear all the debt burden.

This paper sets out to explain the ownership and capital structure of two connected units, that share a common controlling entity. We call them "units", instead of firms or banks, because in our model, as in Leland (2007), there is no explicit production or intermediation activity and hence no real synergy. The controlling entity initially owns the stochastic cash flows from the two activities. It maximizes their value, net of corporate taxes, choosing whether to own them directly, in a horizontal group, or indirectly, in a hierarchical group where one unit, the parent, owns a share of the other unit, the subsidiary. A dividend flows to the parent in proportion to its equity share in the subsidiary. The dividend also depends on the level and the cost of debt, both of which we determine together with ownership. As in trade-off theory, debt provides a tax shield because its interest is deductible from the corporate income. At the same time, higher debt increases the expected default costs.

Our first result is that the value maximizing ownership of units is hierarchical, with a levered parent company that owns $100 \%$ of its subsidiary shares. This result holds for any combination of tax and default cost parameters. This hierarchical arrangement dominates both horizontal and pyramidal groups, in which the parent owns less than $100 \%$ of the shares, because the entire subsidiary dividend flows to the parent before eventually reaching ultimate shareholders. Dividends may thus help the parent repay its own debt, allowing it to better exploit the tax shield.

This ownership result refers however to a special case, that overlooks the presence of 
formal guarantees and informal bailout of affiliates in both industrial and financial groups (see Bodie and Merton, 1992; and Herring and Carmassi, 2009, respectively). Our general analysis therefore allows the parent company to support its profitable but insolvent affiliate as long as both of them survive (as in Boot et al., 1993; and Luciano and Nicodano, 2014). In this enlarged model, debts in the two units become substitutes due to the interplay of ownership and bailout connections. Higher parent debt reduces the level of parent cash flows that remains available for the bailout of the affiliate, leading to lower optimal subsidiary debt and tax shield. Viceversa, higher subsidiary debt reduces the dividend transfer to the parent, and, in turn, optimal parent leverage and tax shield.

Our main result is that full ownership of subsidiary shares remains value maximizing if the income tax rate of the parent company is high enough to induce the parent company to reduce its tax burden through leverage. Value is instead insensitive to subsidiary ownership when the parent company tax rate is small enough so that zero leverage is optimal. Such zero-leverage unit may equally be a proper parent of a fully owned subsidiary, a proper parent in a pyramidal group or a unit in a horizontal group (that we will anyway call the "parent"). The parent gives up its tax savings to provide maximal support to the levered connected unit. This ownership irrelevance result is hard to reconcile with the typical tradeoff intuition, that leads to interior optimal leverage instead of the concentration of all group debt in the subsidiary. The result derives from endogenous debt pricing and costly default. As debt increases, the default probability grows inducing a higher tax-deductible interest spread. At the same time, the deadweight cost of default is mitigated by bailout transfers. Such positive feedback from higher default probability to higher tax savings explains the possibility of total debt shifting onto the subsidiary.

Extant theories of connected units determine internal ownership assuming the extraction of private benefits from control (Zingales, 1995; Chemmanur and John, 1996; Almeida and Wolfenzon, 2006). Ours relies on the idea that an internal dividend helps support upstream units, while preserving them from contagion. We thus contribute a new insight on the role of full subsidiary ownership, while highlighting the distortions deriving from taxes. Prior structural models of leverage in connected units assume exogenous ownership, setting it equal to 100 percent. In one case (Leland, 2007) the focus is on the merger. In the second case 
(Luciano and Nicodano, 2014) the analysis highlights the benefits of the bailout mechanism. There, the dividend payout is set to zero, leading to zero optimal parent leverage, always. Our results explain why parent companies often fully own their subsidiaries in both U.S. multinationals (Lewellen and Robinson, 2013) and European groups (Bloch and Kremp, 1999). The latter also display higher leverage than their subsidiaries (Bianco and Nicodano, 2006; Faccio and Lang, 2002), especially when they receive larger dividend payments (De Jong et al., 2012).

So far the model only considers income taxes, for consistency with prior capital structure literature. However, regulatory authorities restrict group activities because of either governance (Kandel et al., 2015), or tax (OECD, 2016) or financial stability (Herring and Carmassi, 2009) motives. Our structural model allows to infer how group-specific rules impact ownership, leverage, default costs and taxes.

We therefore enrich the tax-bankruptcy trade-off by first considering Intercorporate Dividend Taxes (IDT), that weigh on internal dividends, on top of the taxes on distributions to ultimate shareholders. We show when the obligation to pay IDT makes partial or even zero ownership optimal, possibly augmenting the wedge between ownership and control. This may occur even with a negligible IDT tax rate.

Next, we model Thin Capitalization (TC) rules that place an upper bound on the debt level of the subsidiary in hierarchical groups. An ownership mutation into a horizontal structure avoids these rules, when they are not enforced in each guaranteed unit, provided that the parent tax rate is low. Otherwise, TC rules break ownership irrelevance and always lead to full subsidiary ownership. In this case, debt shifting onto the parent company partially mitigates the impact of TC rules on the tax burden.

Finally, we observe that our initial analysis without bailouts replicates the effects of the so-called Volcker Rule, that prohibits banks from supporting a subsidiary Special Purpose Vehicle (SPV). While the bailout prohibition should intuitively reduce default costs, we show that a combination of IDT and the Volcker Rule may increase them, despite lowering optimal debt, because IDT damage the only remaining internal support channel - the one based on internal dividends. On the contrary, a combination of IDT and TC rules may contain default costs by limiting tax distortions while leaving the bailout channel at work. These last results 
underline that taxes determine financial stability through not only debt levels but internal transfers, as well.

These additional results may also explain some contrasting ownership features of connected units across countries. In the E.U., groups are hierarchical, consistent with the fact that E.U. tax authorities do not tax internal dividends. In the U.S., on the contrary, intercorporate dividends are subject to taxes unless parent ownership exceeds a high threshold. Accordingly, evidence on family ownership (Villalonga and Amit, 2009; Masulis et al., 2011) shows that direct control via a horizontal structure is more common. Other model implications remind aspects of the private equity industry. Like the parent company in our ownership irrelevance proposition, the private equity fund, that may enjoy a special tax status, issues no debt and controls its leveraged portfolio firms, at times contributing to their debt restructurings. Tax savings in the Leveraged Buyout (LBO) deals contribute to value creation (Acharya et al., 2013; Kaplan, 1989), as in our results.

The rest of the paper is organized as follows. Section 2 refers to the related literature, Section 3 presents the model. Section 4 characterizes the optimal internal ownership and leverage choices. Section 5 generalizes the trade-off to IDT, highlighting its interaction with TC and no bailout provisions. Section 6 summarizes some relevant stylized facts. All proofs are in the Appendix.

\section{Related Literature}

This paper contributes to the theory of corporate ownership. Previous models determine the ownership share of minority shareholders, assuming that the controlling entity extracts private benefits from control. In Zingales (1995), the separation of ownership from control, through a pyramid or an alternative mechanism, strengthens the bargaining power of the controlling entity in future control negotiations. Chemmanur and John (1996) study the joint design of debt and ownership of two projects. When the controlling entity has limited wealth, it uses both separate incorporation and debt financing of the subsidiary to protect private benefits from control. In Almeida and Wolfenzon (2006) and Almeida et al. (2011), the controlling entity prefers a direct purchase, without any involvement of minority shareholders, of higher NPV units. It employs instead a listed parent to acquire lower NPV units, 
as this method uses the parent's retained earnings that partly belong to minority shareholders. Our analysis sets private benefits to zero, allowing for positive default costs instead, in order to shift the attention away from minority shareholders and onto lenders. The parent share of subsidiary dividends, and its role in preventing costly default, is the new aspect of ownership we bring to the foreground. Following this insight we offer a new rationale for both hierarchical groups (with full or partial subsidiary ownership by the parent) and horizontal groups, depending on the tax bankruptcy trade off.

This insight advances the understanding of complex organizations, such as multinationals. Huizinga et al. (2008) show that a change in the tax treatment of an affiliate prompts a change in the leverage of all multinational affiliates. This implication carries over to our model, that adds the following three. First, a change in the tax treatment of an affiliate also modifies the ownership share so as to enhance tax savings. For instance, debt shifting towards the parent, due to an increase in its own tax rate, or to the introduction of either TC or no bailout rules, will increase the parent ownership share. Second, ownership taxes exert non linear effects on leverage. Thus, the introduction of IDT shifts debt towards the subsidiary when it generates a pyramid, while it may leave debt unchanged when it dismantles the pyramid as in Morck (2005). Third, the concentration of debt in one affiliate is possible. Due to the endogenous pricing, higher debt increases tax savings not only directly, but also indirectly, through a rise in the tax-deductible interest spread. ${ }^{1}$

Our model innovates with respect to previous structural models of leverage that assume exogenous ownership. They explain that a merger allows for both a higher debt and a higher tax shield, with respect to stand alone units, because its diversified segments support each other. However, the contagion costs may offset the gains stemming from the tax shield when cash flow correlation is moderate (Leland, 2007). This is why a zero-leverage parent that supports its wholly-owned subsidiary exploits both the tax shield and diversification, while avoiding contagion thanks to limited liability (Luciano and Nicodano, 2014). Our paper shows that, with endogenous ownership and positive dividend payout, this zero leverage

\footnotetext{
${ }^{1}$ We are able to study how the enriched trade-off shapes ownership by fixing payout, investment and equity issues. Prior research analyzes the effect of personal dividend taxes on the dividend payout, investment and equity issues (see Chetty and Saez, 2010, and references therein), fixing instead ownership and group-specific taxation.
} 
result implies ownership irrelevance and obtains for low parent tax rates, as long as there are no TC rules and bailout prohibitions. Otherwise, the parent company has positive optimal debt and both dividends and bailouts permit diversification without contagion. Thus, our paper provides a general trade-off theory of ownership and capital structure.

\section{The Model}

This section describes our set-up, that follows Leland (2007) in modeling endogenous leverage and bankruptcy costs. We begin with the case of unconnected units, and then provide details on internal ownership and bailouts.

At time 0, a controlling entity owns two units, $i=P, S$. Each unit has a random operating cash flow $X_{i}$ that is realized at time $T$. We denote with $G(\cdot)$, the cumulative distribution function and with $f(\cdot)$ the density ${ }^{2}$ of $X_{i}$, identical for the two units; $g(\cdot, \cdot)$ is the joint distribution of $X_{P}$ and $X_{S}$ and $\rho$ their correlation. At time 0 , the controlling entity selects the face value $F_{i}$ of the zero-coupon risky debt to issue in each unit, so as to maximize the total arbitrage free value $\left(\nu_{P S}\right)$ of equity, $E_{i}$, and debt, $D_{i}$ :

$$
\nu_{P S}=\max _{F_{P}, F_{S}} \sum_{i=P, S}\left(E_{i}+D_{i}\right)
$$

Each unit pays a flat proportional income tax at an effective rate $0<\tau_{i}<1$ and suffers proportional dissipative costs $0<\alpha_{i}<1$, in the case of default. ${ }^{3}$ Interest on debts are deductible from taxable income. The presence of a tax advantage for debt generates a tradeoff for the unit: on the one hand, increased leverage results in tax benefits, while on the other it leads to higher expected default costs since - everything else being equal - a highly levered unit is more likely to default.

At time $T$, cash flows are distributed after the payment of both corporate income taxes and debt obligations. A unit is declared insolvent when it cannot meet its debt obligations. Its income, net of the deadweight loss due to default costs, is distributed first to the tax authority and then to the lenders. Maximizing the value of debt and equity for the inital

\footnotetext{
${ }^{2}$ As a technical assumption, we require that the density is uni-modal.

${ }^{3}$ No tax credits or carry-forwards are permitted.
} 
owner is equivalent to minimizing the cash flows lost in the form of taxes $\left(T_{i}\right)$ or of default $\operatorname{costs}\left(C_{i}\right)$ :

$$
\nu_{P S}=\min _{F_{P}, F_{S}} \sum_{i=P, S} T_{i}+C_{i}
$$

The expected tax burden of each unit is proportional to the expected taxable income, that is to the operational cash flow $X_{i}$, net of the tax shield $X_{i}^{Z}$. In turn, the tax shield coincides with interest deductions, which are equal to the difference between the nominal value of debt $F_{i}$, and its market value $D_{i}: X_{i}^{Z}=F_{i}-D_{i}$.

It is useful to start with the benchmark case of unconnected, stand alone units. The expected tax burden in each stand alone (SA) unit is equal to:

$$
T_{S A}^{i}\left(F_{i}\right)=\tau_{i} \phi \mathbb{E}\left[\left(X_{i}-X_{i}^{Z}\right)^{+}\right]
$$

where the expectation is computed under the risk neutral probability and $\phi$ is the discount factor (see Leland, 2007). The superscripts and subscripts, $i$, indicate whether the stand alone unit is endowed with the parent $(i=P)$ or subsidiary $(i=S)$ parameters.

Each stand alone unit defaults when its net cash flow is lower than the face value of debt; in other words, default occurs when the level of its realized cash flow is lower than the default threshold, $X_{i}^{d}=F_{i}+\frac{\tau_{i}}{1-\tau_{i}} D_{i}$. Default costs, that are a deadweight loss, are equal to:

$$
C_{S A}^{i}\left(F_{i}\right)=\alpha_{i} \phi \mathbb{E}\left[X_{i} 1_{\left\{0<X_{i}<X_{i}^{d}\right\}}\right]
$$

They increase in the default cost parameter, $\alpha_{i}$, as well as in (positive) realized cash flows when the unit goes bankrupt. A rise in the nominal value of debt, $F_{i}$, increases the default threshold, $X_{i}^{d}$, thereby increasing the expected default costs.

It is possible to show that the tax shield of a stand alone unit is a convex function of $F_{i}$. Increasing the nominal value of debt increases the tax shield, thereby reducing the tax burden because the market value of debt, $D_{i}$, increases with $F_{i}$ at a decreasing rate (reflecting a higher risk). On the contrary, the default threshold $X_{i}^{d}$ is concave in the face value of debt, $F_{i}$. Luciano and Nicodano (2014) prove that a stand alone unit has positive optimal debt if the sum of tax burden and default costs is convex in the face value of debt. The Appendix 
shows that it raises positive debt even if the riskfree rate is zero, because of the endogenous spread.

The following section allows for transfers between units, that affect both the expected default costs and the spread associated to a given level of debt.

\subsection{Internal Ownership and Bailouts}

This section provides details on linkages between units. We first model internal ownership and bailout transfers that characterize complex organizations, allowing for IDT. Next, we assess how the two links impact on both the tax burden and the default costs of the group, given exogenous debt levels.

The parent owns a fraction, $\omega$, of its subsidiary equity. When $\omega=1$, the parent fully owns its subsidiary, giving rise to a hierarchical group. The controlling entity owns the subsidiary only indirectly, a case that appears in the left-hand side of Figure 1. When $\omega=0$, there is no parent ownership. The controlling entity will either own the subsidiary directly, or will sell it to outside shareholders or both, as in the right-hand side of Figure 1 . This is the case of a horizontal group. The intermediate case, where the connected units constitute a pyramidal group, is a mix of parent, controlling and/or outside shareholding. ${ }^{4}$

The subsidiary distributes its profit after paying the tax authority and lenders, $\left(X_{S}^{n}-\right.$ $\left.F_{S}\right)^{+}$, where $X_{S}^{n}$ are its cash flows, net of corporate income taxes. Assuming a unit payout ratio, the parent receives a share $\omega$ of the subsidiary profits at time $T$. Let the tax rate on the intercorporate dividend be equal to $0 \leq \tau_{D}<1$. Consequently, the expected present value of the after tax internal dividend is equal to:

$$
I D=\phi \omega \mathbb{E}\left[\left(1-\tau_{D}\right)\left(X_{S}^{n}-F_{S}\right)^{+}\right]
$$

The cash flow available to the parent, after receiving the internal dividend, increases to:

$$
X_{P}^{n, \omega}=X_{P}^{n}+\left(1-\tau_{D}\right) \omega\left(X_{S}^{n}-F_{S}\right)^{+}
$$

\footnotetext{
${ }^{4}$ The controlling entity in this model has no role but the design of ownership and capital structure. It may keep control without ownership, with tools used by families (see Villalonga and Amit, 2009), SPVs and private equity.
} 


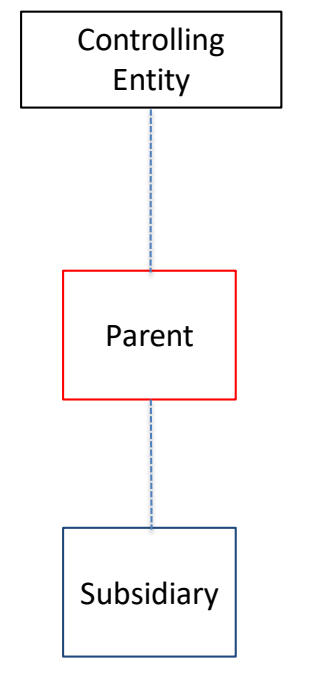

Fully owned
subsidiary $(\omega=1)$

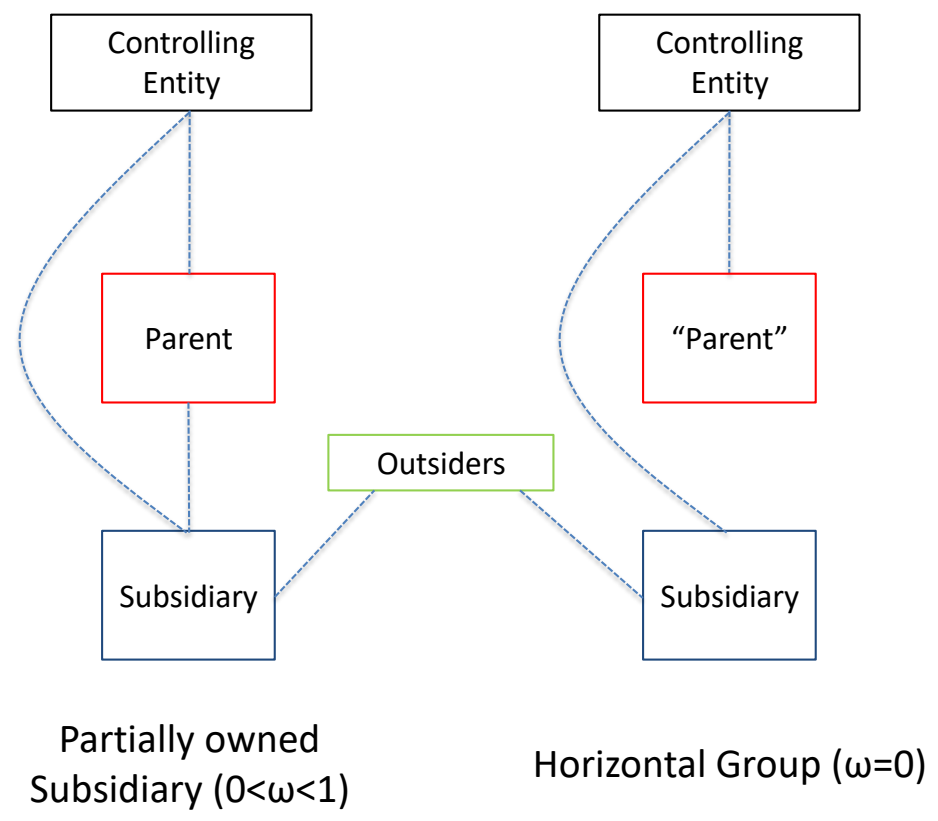

Partially owned $\quad$ Horizontal Group $(\omega=0)$
Subsidiary $(0<\omega<1) \quad$

Figure 1: This figure depicts the three organizations that our model can reproduce: a parent with its fullyowned subsidiary (left panel), a parent that partially owns its subsidiary (center panel) and a horizontal group (right panel). Blue dotted lines represent the possible ownership links.

Equation (6) indicates that internal dividends provide the parent with an extra buffer of cash that can help it remain solvent in adverse contingencies in which it would default as a stand alone company. It follows that the dividend transfer generates an internal rescue mechanism, whose size increases in the parent ownership, $\omega$, and falls in the dividend tax rate, $\tau_{D}$, given the capital structure. Equation (6) highlights that internal flows are useful for avoiding the parent company's default, instead of serving for financing investment projects, as in Stein (1997).

We do not analyze personal dividend and capital gains taxation levied on ultimate shareholders. Therefore, we assume that the positive personal dividend (and capital gains) tax rate is already included in $\tau_{i}$, which is indeed an effective tax rate. We also assume that the personal tax rate on distributions is equal across the parent and the subsidiary, so as to rule out straightforward tax arbitrage between the two. 
Another characteristic of connected units is the internal bailout, that we model following Luciano and Nicodano (2014). The parent transfers cash flows to the other unit if the latter, which is insolvent but profitable $\left(0<X_{S}^{n}<F_{S}\right)$, becomes solvent thanks to the transfer $F_{S}-X_{S}^{n}$, while the parent remains solvent $\left(X_{P}^{n}-F_{P} \geq F_{S}-X_{S}^{n}\right) .^{5}$

As in Luciano and Nicodano (2014), there is limited liability of the parent unit with respect to the debt of its subsidiary, even in the limiting case when the parent is the sole owner of its subsidiary. Since neither dividends nor the bailouts affect the solvency of the provider, they differ from both internal loans and unconditional guarantees, that help the recipient unit service its debt but impair the service of the giver's debt. The model also assumes that the assets of the subsidiary are subject to the claims of the parent lenders, should the parent default, if internal ownership is positive. ${ }^{6}$ Thus dividends (like loans and unconditional guarantees) are not conditional on the parent survival, while bailouts are contingent on positive subsidiary cash flows. This asymmetry implies that dividends are costlier than bailouts, affecting the trade-off between parent and subsidiary debt. Clearly, it is possible to model a zero dividend payout contingent on the parent default, making dividends exactly symmetric to bailouts. However, we stick to an unconditional payout, that captures the ability for parent's lenders to recover subsidiary profits through a revocatory action.

We can now show how internal dividends and the bailout transfer affect default costs and the tax burden of the group.

\subsection{The Tax Bankruptcy Trade-Off in Complex Organizations}

This section amends the tax-bankruptcy trade-off for the presence of both the bailout and internal dividends. Below we analyze their change given the debt levels, $F_{P}$ and $F_{S}$, that will become endogenous later on.

As in Luciano and Nicodano (2014), the bailout transfer never increases the default costs in the subsidiary, $C_{S}$, and leaves both the default costs of the parent and the tax burden of

\footnotetext{
${ }^{5}$ In a static model, the ex-post enforcement of bailouts must rely on courts. In practice, enforcement mechanisms vary from reputation (Boot et al., 1993) to the purchase of the junior tranche by the sponsoring parent (De Marzo and Duffie, 1999).

${ }^{6}$ See the case of the Ferruzzi group restructuring (Penati and Zingales, 1997).
} 
the group unaffected. The reduction in expected default costs $(\Gamma)$ is equal to:

$$
\Gamma=C_{S A}^{S}\left(F_{S}\right)-C_{S}=\alpha_{S} \phi \mathbb{E}\left[X_{S} 1_{\left\{0<X_{S}<X_{S}^{d}, X_{P} \geq h\left(X_{S}\right)\right\}}\right] \geq 0
$$

where the indicator function $1_{\{\cdot\}}$ defines the set of states of the world in which the rescue occurs, that is when the subsidiary defaults without transfers (first term) and the parent funds are sufficient for rescue (second term). The shape of the function $h$, which is defined in the Appendix, implies that the rescue by the parent is likelier the smaller the parent debt, $F_{P}$.

Dividends leave the subsidiary trade-off unchanged, affecting however both the default costs and the tax burden of the parent. On the one hand dividends add to the cash flow in the parent - as in equation (6) - increasing the chances that the parent is solvent. On the other hand, they also increase the lenders' recovery rate in insolvency, should the parent go bankrupt anyway. This last feature differentiates internal dividend transfers from the bailout transfers described earlier. It captures the asymmetry of limited liability in groups, that protects the parent from but subjects the subsidiary to the claims of the other unit lenders.

Default costs saved by the parent, $\Delta C$, are then equal to:

$$
\begin{aligned}
\Delta C & =C_{S A}^{P}\left(F_{P}\right)-C_{P}=\alpha_{P} \phi \mathbb{E}\left[X_{P} 1_{\left\{0 \leq X_{P}<X_{P}^{d}, X_{S} \geq k\left(X_{P}\right)\right\}}\right]+ \\
& -\alpha_{P} \phi \mathbb{E}\left[\omega\left(1-\tau_{D}\right)\left(X_{S}^{n}-F_{S}\right) 1_{\left\{X_{P}<X_{P}^{d}, X_{S}<k\left(X_{P}\right)\right\}}\right]
\end{aligned}
$$

where $k\left(X_{P}\right)$ is defined in the Appendix. The first term measures the default costs saved when the parent avoids insolvency thanks to the dividend transfer. The second term equals the default costs on the dividend, when it is insufficient to repay parent debt. Lemma 1 in the Appendix shows that $\Delta C$, under our assumptions, is non-increasing in $F_{S}$ and nondecreasing in internal ownership. Indeed, both higher subsidiary debt and lower ownership share decrease the dividend transfer.

Finally, dividends increase the group tax burden above the one of stand alone units 
because of IDT. We denote this change as $\Delta T$, defined as:

$$
\Delta T=T_{S}+T_{P}-T_{S A}^{P}\left(F_{P}\right)-T_{S A}^{S}\left(F_{S}\right)=\phi \omega \tau_{D} \mathbb{E}\left[\left(X_{S}^{n}-F_{S}\right)^{+}\right] \geq 0
$$

The simultaneous presence of bailout and dividend transfers originates a trade-off between parent and subsidiary debt. The higher the subsidiary debt, the lower the dividends, given the ownership share. Lower dividends result in higher default costs in the parent, at each level of debt. Similarly, increasing parent debt reduces subsidiary support in the subsidiary through the bailout guarantee. ${ }^{7}$

\section{Ownership and Capital Structure}

This section determines the capital structure $\left(F_{P}\right.$ and $\left.F_{S}\right)$ and the internal ownership share $\omega$ that minimize total default costs and tax burdens of the two units, solving:

$$
\min _{F_{S} \geq 0, F_{P} \geq 0,0 \leq \omega \leq 1} T_{S}+T_{P}+C_{S}+C_{P}
$$

Throughout the paper, we maintain the standard technical assumption of convexity of the objective function. We report the Kuhn-Tucker conditions associated with the minimum program at the beginning of Appendix B. We denote the optimal debt levels and ownership, solving (9), as $F_{S}^{*}, F_{P}^{*}, \omega^{*}$. The value-maximizing organization may result in a hierarchical group, $\omega^{*}=1$, a pyramid $0<\omega^{*}<1$, or a horizontal group, $\omega^{*}=0$.

Section 4.1. presents the main theorem of this paper, assuming no IDT. The model allows to compute several endogenous magnitudes, including taxes, the dividend and bailout transfers, the value of debt and equity - beyond the book value of debts and the ownership share. A presentation of two numerical exercises, based on Leland (2007) calibration, allows to appreciate the heterogeneity of optimal capital structure for units with the same taxbankruptcy parameters.

\footnotetext{
${ }^{7}$ The trade-off is sharpest if the payout can be set to zero when the parent defaults; in other words, if the parent company lenders cannot file a revocatory action to recover their dividends. Savings in default costs become non-decreasing in internal ownership, for any density, and dividends become the mirror image of bailouts.
} 


\subsection{Optimal Hierarchical Groups}

Let us first consider the optimal choice of ownership without bailouts. In this case, full subsidiary ownership is optimal. In fact, stand alone firms face default costs because they always have positive optimal leverage (see Luciano and Nicodano, 2014). The ownership link improves the tax bankruptcy trade-off by decreasing default costs in the parent, at the stand alone level of debt, without worsening the tax-bankruptcy trade-off in the subsidiary.

\section{Theorem 1. No bailout.}

Let there be no bailout and no IDT $\left(\tau_{D}=0\right)$. Then: (i) the optimal subsidiary ownership is full $\left(\omega^{*}=100 \%\right)$ and the parent has positive leverage ( $\left.F_{P}^{*}>0\right)$; (ii) optimal debt in the parent exceeds the one in a stand alone unit $\left(F_{P}^{*}>F_{S A}^{P *}\right)$, when the condition (B.9) in the Appendix holds; (iii) if the units are equal $\left(\tau_{S}=\tau_{P}, \sigma_{S}=\sigma_{P}, \alpha_{S}=\alpha_{P}\right), F_{P}^{*} \geq F_{S A}^{P *}$ for every $\rho>\bar{\rho}(\tau, \alpha, \sigma)$.

This theorem implies that internal dividends are value increasing. They allow the parent company to raise additional debt relative to a comparable stand alone unit, under sufficient conditions. Internal dividends potentially save a larger share of parent cash flow when both its debt and the associated default threshold increase. However, the chances that the dividend itself is insufficient to save the parent and that, as a consequence, it is lost in the default of the parent, also increase in parent debt. The condition (B.9) in the Appendix requires that a marginal increase in parent debt from its stand-alone debt level, when $\tau_{D}=0$, lowers default costs, including those associated with dividend losses. While it is difficult to sign condition (B.9) in general, it is less likely to hold if the subsidiary tax rate is higher. Indeed, higher optimal subsidiary debt and default threshold reduce both its expected dividend and the chances of rescue. The same effect derives from an increase in cash flow volatility, which also adds to the chances that $1 \$$ dividend is lost in the parent default. Other tax/bankruptcy parameters display a complex impact. ${ }^{8}$ Section 5.3 sheds further light on optimal parent debt

\footnotetext{
${ }^{8}$ For instance, a higher parent tax rate increases both the optimal parent debt and the default threshold. This may increase the default costs saved through dividends if the probability of successful rescue does not decrease too much, a possibility that depends on the exact shape of the cash flow distribution. However, it also increases the expected amount of dividends lost in the parent default, which may lead to a violation of condition (B.9).
} 
relative to the stand-alone counterpart, by specializing on Gaussian cash flows, also highlighting a violation of the condition in Theorem 1ii). The condition in part (iii) of the theorem requires a high enough cash flow correlation, so that parent and subsidiary cash flow realizations are close if units are equal. Expected dividend transfers are then relatively small compared to the expected parent cash flows, ensuring that expected default costs saved in the parent exceed expected foregone dividends. Hence, increasing parent debt above the stand-alone level increases value.

In the general case where bailouts are allowed, there is a tension between the payment of internal dividends and the bailout transfer. An opposite incentive, to exploit the value of the bailout through larger subsidiary debt and smaller parent debt, counterbalances the effect described in Theorem 1. The following theorem characterizes the optimal internal ownership and capital structure, allowing for bailouts but maintaining the absence of dividend taxes.

Theorem 2. Let there be bailouts and no IDT $\left(\tau_{D}=0\right)$. Then, there exist a $z\left(\tau_{S}, \alpha_{S}, \rho\right)>0$ and $a z^{\prime}\left(\tau_{S}, \alpha_{S}, \rho\right) \geq z>0$ such that:

(i) if $\tau_{P}<z$, then subsidiary ownership is indefinite. Moreover, the parent has zero leverage $\left(F_{P}^{*}=0\right)$. Finally, the group debt exceeds the debt of two comparable SA firms if and only if the ratio of default cost rate to tax rate in the subsidiary is below a constant $Q$;

(ii) If $\tau_{P} \geq z^{\prime} \geq z$, then the parent fully owns its subsidiary $\left(\omega^{*}=1\right)$. Moreover, it has positive optimal debt $\left(F_{P}^{*}>0\right)$.

Part (i) of the theorem is an ownership-irrelevance proposition. It implies that horizontal groups, along with hierarchical and pyramidal groups, deliver the same value to their shareholders, if the parent tax rate, $\tau_{P}$, is sufficiently low. On the contrary, Part (ii) states that only hierarchical groups with full internal ownership maximize value when the tax rate of the parent is high enough. The explanation for these ownership patterns is possible thanks to their joint characterization with optimal capital structure. Under the conditions of Part (i), the parent raises no debt. Zero leverage maximizes the magnitude of the set of states in which the parent is able to provide a bailout transfer, allowing for both large subsidiary debt and tax gains. It also maximizes the tax burden in the parent company, whose value is however limited for a sufficiently low parent tax rate. In this case, the total debt raised by 
the group is greater than that of two stand alone units, if the ratio of the default cost rate to the tax rate in the subsidiary is bounded.

When the conditions of Part (ii) apply, the parent no longer specializes in providing support, because it gains more from increasing its own tax shield than from lowering the cost of debt financing in the subsidiary via larger bailout transfers. Subsidiary dividends, in turn, help service parent debt, thereby allowing it to increase its own tax shield. Thus, Part (ii) indicates that full subsidiary ownership may be optimal not only under the assumption of no bailouts in Theorem 1 but in the general case, as well. The result of Part (ii) radically departs from the one in Theorem 2 in Luciano and Nicodano (2014), which indicates optimal zero parent leverage, for three reasons. First, our model endogenously determines subsidiary ownership, that is assumed to equal 100\% in Luciano and Nicodano (2014). Second, we allow for a positive dividend payout which is set to zero in Luciano and Nicodano (2014). Third, we allow for different tax rates in the two units. In sum, Luciano and Nicodano (2014) highlight a striking special case of capital structure, revealing the power of bailouts when both the cost of debt and default are endogenous. Our Theorem 2 is a trade-off theory of capital and ownership structure.

The cut-off parent tax rate levels, $z$ and $z^{\prime}$, are increasing in $\tau_{S}$ and inversely u-shaped in $\alpha_{S}$. A higher corporate tax rate in the subsidiary increases the likelihood that the parent has zero leverage, because of higher marginal tax savings obtained from additional subsidiary debt. In turn, a higher default cost rate in the subsidiary triggers two effects. On the one hand it makes the parent support more valuable, in the set of states when rescue succeeds. On the other hand, it increases the cost of subsidiary debt and the default threshold, making it more likely that the subsidiary will default. For low $\alpha_{S}$, the first effect prevails and the cut-off levels increase together with the chances of zero parent leverage, while the second effect overcomes for high $\alpha_{S}$.

\subsubsection{Understanding Heterogeneous Ownership and Leverage}

This section illustrates, by means of a numerical example, how the tax bankruptcy tradeoff shapes groups, their leverage and their internal capital market. The tables below show the characterization of the group for different parametric combinations, when cash flows 
are jointly Normally distributed. Table 1 displays the effect of changes to both the parent tax rate and cash flow volatility. It will help understand the heterogeneity in firm capital structure and valuation, the complementarity between debt and non-debt tax shields and the asymmetric consequences of dividends and bailouts. Table 2 will reveal that optimal debt can be lower in more diversified groups. Both tables display several endogenous variables including the ownership share in the subsidiary and the optimal face value of debt. The expected present value of cash flows is set to 100 in each unit, so as to standardize each endogenous balance sheet item highlighted in the rows.

In Table 1, the third column adopts the benchmark parametrization of Leland (2007) for BBB-rated firms, with the exception of the cash flow correlation among affiliates (set to 0.8). All parameters are equal across units. With both corporate tax rates at $20 \%$, subsidiary ownership turns out to be irrelevant for group value. The expected bailout transfer is large (47.74), supporting the high subsidiary debt (183) and containing its cost (resulting from the difference between the face and the market value of debt, that is 183-133.58). Such high debt implies high expected default costs (1.91), despite the bailout transfer, but allows for a low expected tax burden (12.45) compared to the one of the zero-leverage parent (20.01). The expected dividend, which is distributed to the parent only if the group is hierarchical, is negligible precisely because of the large service of subsidiary debt.

A higher parent tax rate, $26 \%$ vs. $20 \%$, leads to a hierarchical group with $100 \%$ subsidiary ownership (as in both the first and second columns). In the second column, when all other parameters follow Leland (2007) choices, the large internal dividend (79.30) supports the highly-levered parent (158), that enjoys a relatively low tax burden (18.97) when considering the $26 \%$ tax rate, while the almost zero-leverage subsidiary pays higher taxes (19.98) despite its lower tax rate. In the second column, as in the benchmark case, capital structure is extreme. The group may also display a more balanced capital structure, as in the first column, where the standard deviation of cash-flows is twice as large as in the previous case. Higher risk makes the tax shield more valuable, because the unit pays taxes when profitable but does not receive refunds when unprofitable. Increased volatility also implies that dividends will more likely be lost in the default of the parent. This induces a substitution effect towards subsidiary debt, relative to the lower volatility case. The group exploits in 


\begin{tabular}{|c|c|c|c|}
\hline \multicolumn{3}{|c|}{ Table 1: Group Structure, Parent Tax Rates and Cash Flow Volatility } \\
\hline \multicolumn{2}{|c|}{ Full ownership } & Ownership irrelevance \\
\hline Value $(\nu)$ & $\tau_{P}=26 \%, \sigma=44 \%$ & $\tau_{P}=26 \%, \sigma=22 \%$ & $\tau_{P}=20 \%, \sigma=22 \%$ \\
\hline Ownership share $(\omega)$ & $165.50(77.63 ; 87.87)$ & $160.52(159.74 ; 0.78)$ & $166.32(32.74 ; 133.58)$ \\
Face Value of Debt $(F)$ & $100 \%$ & $100 \%$ & Any \\
Debt Value $(D)$ & $182(40 ; 142)$ & $159(158 ; 1)$ & $183(0 ; 183)$ \\
Cum-Dividend Equity Value $(E)$ & $118.09(30.22 ; 87.87)$ & $123.70(122.92 ; 0.78)$ & $133.58(0 ; 133.58)$ \\
Default Costs $(C)$ & $2.30(47.42 ; 14.88)$ & $116.12(36.82 ; 79.30)$ & $33.17(32.74 ; 0.43)$ \\
Tax Burden $(T)$ & $38.69(25.14 ; 13.55)$ & $38.95(18.97 ; 19.98)$ & $32.45(20.01 ; 12.45)$ \\
Dividend Transfer $(I D)$ & 14.88 & 79.30 & $0.43 \times \omega$ \\
Bailout Transfer $(B)$ & 15.35 & 0 & 47.74 \\
Dividend lost in Parent Default & $5.31 \%$ & $1.65 \%$ & 0 \\
Value of SA units & $164.91(80.07 ; 84.84)$ & $158.52(77.05 ; 81.47)$ & $162.94(81.47 ; 81.47)$ \\
\hline
\end{tabular}

Table 1: This table displays the optimal group structure with different parametric combinations, leading to full ownership or ownership irrelevance. Unspecified parameters follow the base-case in Leland (2007): $\alpha_{P}=\alpha_{S}=23 \%, \tau_{S}=20 \%, \phi=0.78, T=5$. Cash flows are jointly Gaussian, with correlation $\rho=-0.8$. $\sigma_{S}=\sigma_{P}=\sigma$ is the annualized percentage volatility of cash flows; $\tau_{D}=0$. Their discounted expected value is $\phi \mathbb{E}\left[X_{S}\right]=X_{0}^{S}=\phi \mathbb{E}\left[X_{P}\right]=X_{0}^{P}=100$. Parent and Subsidiary figures are in brackets. The subsidiary Cum-Dividend Equity Value includes the dividend transferred to the parent. Value is the sum of the debt and equity (net of dividend) claims in each unit.

this case both support channels.

In all the columns, connected companies display larger value than stand alone companies, reported in the last row of the table. This value difference increases as cash flow volatility falls (from the first to the second column) and as the parent tax rate falls (from the second to the third column). The reason is that fewer dividends are lost in the parent default $(5.31 \%$ vs. $1.65 \%$ vs. $0 \%$ in the three columns respectively). Indeed, the subsidiary tends to pay high dividends when the parent has highly negative cash flows, due to negative cash flow correlation. Lower cash flow volatility reduces the occurrence of both parent default and dividend losses, at a given debt level, inducing a substitution away from subsidiary debt. A lower tax rate differential between the parent and its subsidiary lowers optimal parent debt, reducing the chances of losing dividends. ${ }^{9}$ In the limiting case of the third column, the parent issues no debt and no dividend is lost.

Four insights derive from this exercise. First, the heterogeneity of optimal leverage in units with the same tax-bankruptcy parameters, observed by Bernanke, Campbell and Whited (1990), arises from transfers between connected units. Indeed, the subsidiary in the

\footnotetext{
${ }^{9}$ The same patterns hold in the absence of bailouts, provided cash flow correlation is low enough. See Table 4 .
} 
third column displays the same tax-bankruptcy parameters of the subsidiary in the second column, but has much higher debt (183 vs. 1). An intermediate case is the stand alone unit, that has debt equal to 57.

Second, cum-dividend equity values fall - holding cash flows fixed - because of either higher debt, or larger transfers to the lenders of supported units or both. For instance, subsidiary equity value is as low as 0.43 in the third column while parent equity value drops to 0.78 in the second column, when they raise all the group debt. Importantly, the value of group equity is often lower than the (unreported) equity value of two stand alone units. For instance, the total equity value is equal to 33.17 in the parametrization of the third column versus 78.64 in the stand alone case. This occurs because on the one hand the parent transfers bailout funds to lenders while, on the other, the subsidiary raises all group debt. Since there is no inefficiency, the mirror image of a lower equity value is a higher value of debt (also when compared to the case of an equal face value of debt and no bailouts).

The third takeaway regards the relationship between non-debt tax sheltering and the debt tax shield. In a stand alone unit, they are substitutes (De Angelo and Masulis, 1980; Graham and Tucker, 2006) because the reduction in the effective corporate income tax weakens the incentive to raise debt. In connected units, they can become complements. Consider in fact a non-debt tax shelter, such as the incorporation of the parent in a lower tax rate jurisdiction. The consequences of this choice are represented by the change from the second to the third column. Optimal debt increases (from 159 to 183), because the subsidiary has unchanged tax rate while the lower parent tax rate permits the provision of larger bailout funds.

The last insight concerns the asymmetry between dividend and bailouts. When the units display the same tax and default cost rates, as in the third column of Table 1, zero parent debt is optimal. This pattern indicates that the bailout guarantee is more valuable than the dividend transfer, the more so the lower is cash flow correlation. Indeed, a share $\alpha_{P}$ of dividends gets lost when the parent defaults, while the bailout is conditional on the survival of the subsidiary. ${ }^{10}$ This asymmetry also implies that an increase in the overall tax rate for the group may reduce total optimal debt, while in traditional trade-off theory debt always

\footnotetext{
${ }^{10}$ Recall that this modeling captures the fact that a proper parent company has claims to subsidiary's assets, while the parent company enjoys limited liability.
} 
increases. This is visible when we track the increase in the parent income tax rate from 20 to 26 percent. As the parent tax rate increases above the threshold, $z^{\prime}$, it pays the parent to raise debt using dividend support. However, dividend support is costlier than bailouts, as a share of dividends is lost in the parent bankruptcy. This explains the lower optimal debt for the group. ${ }^{11}$

Table 2 displays the structure of a hierarchical group as cash flow correlation varies. We stick to the same parameters as in the first column of the previous table, but change to a lower subsidiary tax rate that ensures full subsidiary ownership. As correlation increases, so do total debt and total default costs, while total taxes decrease. This pattern reverses the intuition "more diversification leads to higher debt capacity" that holds in a conglomerate merger (Leland, 2007). The logic is as follows. The parametric combination "negative correlation and high cash flow volatility" limits both optimal parent debt, despite the high tax rate differential, and total debt, otherwise foregone dividends would be too high. When correlation turns positive, the chances of simultaneous realizations of high dividends and low parent cash flows decrease, limiting dividend losses at a given debt level. As a consequence, both the optimal parent and total debt grow, also relative to subsidiary debt, exploiting the favorable tax rate differential. ${ }^{12}$

Let us stress that there is another reason why optimal debt increases in correlation. This is most evident when ownership is irrelevant (for the Leland (2007) base case parameters) and when only bailouts are at work, as in Luciano and Nicodano (2014). Bailouts mitigate the deadweight default cost only if both cash flows are positive. With positive correlation, optimal debt is higher because contemporaneous realizations of positive cash flow in the parent and positive cash flow in an insolvent subsidiary are frequent, increasing the chances of bailouts. ${ }^{13}$

\footnotetext{
${ }^{11}$ Clearly, an increase in the subsidiary tax rate from 20 to 26 percent impacts total debt as in the trade-off theory for stand alone units.

${ }^{12}$ This effect tends to disappear if we let volatility fall sufficiently, because foregone dividends become negligible also with negative cash flow correlation.

${ }^{13}$ Lenders' losses upon default will also increase in correlation, because default with negative cash flow becomes more frequent relative to default with positive cash flow. This widens lenders' required spread which, being tax-deductible, leads to higher tax savings. In other words, the shift from recovery upon default (when correlation is low) to higher spread (when correlation is high), while neutral to lenders who always break even, enjoys a tax incentive.
} 


\begin{tabular}{|c|c|c|c|c|c|}
\hline \multicolumn{5}{|c|}{ Table 2: Hierarchical Group Structure and Cash Flow Correlation } \\
\hline \multicolumn{5}{|c|}{ Correlation } \\
\hline Value $(\nu)$ & -0.8 & -0.5 & 0 & 0.5 \\
\hline Ownership share $(\omega)$ & $168.20(129.48 ; 38.72)$ & $167.92(98.17 ; 69.74)$ & $168.49(101.95 ; 66.54)$ & $169.71(129.12 ; 40.59)$ & $171.56(128.08 ; 43.48)$ \\
Face Value of Debt $(F)$ & $100 \%$ & $100 \%$ & $100 \%$ & $100 \%$ & $100 \%$ \\
Debt Value $(D)$ & $151(95 ; 56)$ & $178(66 ; 112)$ & $202(88 ; 114)$ & $241(176 ; 65)$ & $258(187 ; 71)$ \\
Cum-Dividend Equity Value $(E)$ & $111.96(73.24 ; 38.72)$ & $117.29(47.55 ; 69.74)$ & $122.71(56.17 ; 66.54)$ & $132.69(92.10 ; 40.59)$ & $135.27(91.79 ; 43.48)$ \\
Default Costs $(C)$ & $108.54(56.24 ; 52.30)$ & $77.24(50.62 ; 26.62)$ & $71.94(45.78 ; 26.16)$ & $84.83(37.00 ; 47.83)$ & $81.08(36.28 ; 44.80)$ \\
Tax Burden $(T)$ & $1.60(1.41 ; 0.19)$ & $3.54(1.53 ; 2.01)$ & $5.80(2.77 ; 3.03)$ & $10.24(8.92 ; 1.32)$ & $10.74(9.04 ; 1.70)$ \\
Bailout Transfer $(B)$ & $37.65(23.01 ; 14.64)$ & $35.61(23.59 ; 12.02)$ & $32.76(21.27 ; 11.49)$ & $27.10(13.22 ; 13.88)$ & $25.28(11.74 ; 13.54)$ \\
Dividend Transfer $(I D)$ & 2.33 & 6.83 & 3.70 & 0.09 \\
Dividend Lost in Parent Default & 52.30 & 26.62 & 26.16 & 47.83 \\
\end{tabular}

Table 2: Cash flows are jointly Gaussian with $X_{0}^{S}=X_{0}^{P}=100, \sigma_{S}=\sigma_{P}=\sigma=44 \%$. The parameters are $\tau_{P}=0.26, \tau_{S}=0.16, \alpha_{P}=\alpha_{S}=0.23, \tau_{D}=0, \phi=0.78, T=5$. Parent and Subsidiary figures are in brackets. Cum-Dividend Equity Value is the value of equity in each unit, that, for the subsidiary, includes the dividend transferred to the parent. Value is the sum of the debt and equity claims in each unit, where subsidiary equity value is ex-dividend.

In this section, we have considered no other duty beside corporate income taxes so as to nest prior results. The next section allows for a tax-bankruptcy trade-off that also encompasses group-specific regulatory provisions.

\section{A Generalized Tax Bankruptcy Trade-off}

Connected units are of interest to regulators because of either governance, or tax receipts or financial stability motives. IDT have a governance rationale. According to Morck (2005), IDT help dismantle pyramids, that permit the expropriation of minority shareholders when the controlling entity enjoys private benefits from control. TC rules and "no bailout" rules respectively stem from a tax receipt and a financial stability rationale. Major OECD countries impose TC rules, and enforce them especially on domestic subsidiaries of foreign groups to limit interest deductions. Finally, the Volcker Rule (i.e. Section 619 of the Dodd-Frank Act) amends the Bank Holding Company Act of 1956, prohibiting banking entities from rescuing their Special Purpose Vehicles. In the UK, the Banking Reform of 2013 similarly rules out the voluntary support by depository institutions to other financial entities in distress within the same bank holding company (see Segura, 2017). In Korea, units of large chaebols cannot provide guarantees to other domestic affiliates (Kim et al., 2007). Against this background, we generalize the tax-bankruptcy trade-off to allow for group-specific provisions. Our positive analysis will highlight optimal changes in ownership, in the tax burden and in default costs. 
Section 5.1 focuses on IDT. Sections 5.2 and 5.3 will in turn highlight the interaction of IDT with TC rules and "No Bailout" rules. Section 5.4 hints at an additional group-specific provision, namely tax consolidation.

\subsection{IDT and optimal ownership mutations}

The following theorem characterizes optimal subsidiary ownership (and capital structure) in the presence of IDT.

\section{Theorem 3. IDT.}

Let there be bailouts. Then the introduction of a tax on the intercorporate dividend transforms a hierarchical group into either (i) a pyramid or a horizontal group $\left(0 \leq \omega^{*}<1\right)$ if $\tau_{D}>\underline{\tau}_{D}>0$ and $\tau_{P}>z^{\prime}$; or (ii) a horizontal group $\left(\omega^{*}=0\right)$ if either $\tau_{D}>\bar{\tau}_{D} \geq \underline{\tau}_{D}>0$ or $\tau_{P}<z$. In the latter case, neither the value nor the leverage of the group are affected.

In line with Morck (2005), this theorem highlights the ability of IDT to dismantle hierarchical groups, by imposing a double taxation of dividends. However, Morck (2005) stresses that IDT dismantle pyramids, assuming they are the optimal way the controlling entity achieves a control wedge. On the contrary, Theorem 2 and 3 together imply that IDT is necessary for a pyramid to be the only value maximizing group structure.

If irrelevance was prevailing prior to the introduction of IDT, the theorem indicates that ownership transforms in response to even a negligible IDT tax rate. In this case, value is insensitive to changes in the ownership - control wedge, reminding results in Demsetz and Lehn (1985). On the contrary, the introduction of a tax on ownership such as IDT affects optimal leverage when a hierarchical group was optimal (see the proof for details). The reason is that this tax impairs support to the parent company, which reduces its leverage if the IDT tax rate exceeds the cut-offs identified in the theorem.

Extensive numerical analysis shows that the cut-off $\underline{\tau}_{D}$ is increasing in $\tau_{P}$ and $\alpha_{S}$, and decreasing in $\tau_{S}$ and $\alpha_{P}$. Indeed, $\underline{\tau}_{D}$ increases when it is more profitable to increase debt in the parent (higher own tax rate and lower own default cost rate; lower tax rate and higher

default cost rate for the subsidiary), increasing the marginal value of dividends. The cut-off level $\bar{\tau}_{D}$ responds to changes in the parameters exactly like $\underline{\tau}_{D}$.

We summarize some implications of Theorem 3 in the following corollary: 
Corollary 1. (i) The presence of IDT is a necessary condition for a pyramid to be the only value maximizing structure.

(ii) An infinitesimal IDT tax rate may lead to total separation between ownership and control. (iii) Even a 100\% IDT tax rate may leave group value unchanged.

A few remarks are necessary to better clarify the implications of our theorem. First, the dismantling result in Theorem 3ii) holds as long as the payout ratio is positive and inflexible. Such assumption reflects the observation that dividend payouts for corporate shareholders appear not to adjust to corporate tax clienteles (Barclay et al., 2009; Dahlquist et al., 2014). Second, recall that we collapsed the personal dividend tax into the effective corporate income tax to avoid cumbersome notation. Theorem 2 and Theorem 3 hold as long as the personal tax rate on dividends from the parent is the same as the one on dividends from its subsidiary. Otherwise, the shift from indirect to direct ownership may no longer be value neutral, also with a zero-leverage supporting unit.

Third, recall that the notation $\omega=0$ captures both horizontal groups with positive direct ownership by the controlling entity as well as orphan subsidiaries entirely held by outsiders. The reader may wonder whether the parent still bails out its subsidiary when it sells out its cash flows by setting internal ownership to zero. It is easy to allow for an endogenous probability of bailout, set by the controlling entity. The ex-ante value maximizing probability is equal to one, indicating that subsidiary bailouts increase tax gains and value. ${ }^{14}$ The reason is that outsiders will pay a higher price for investing in the orphan subsidiary, anticipating the conditional bailout transfer.

Fourth, so far there are no costs associated with ownership transformations. These can be sizable when real synergies explain the group structure, thereby limiting the ownership adjustments highlighted in Table 1 and Theorem 2. We discuss the effects of such costs after considering TC and prudential rules.

\subsection{TC rules}

Tax authorities observe that guaranteed subsidiaries display thin equity capital due to the combination of bailout guarantees and tax shield. Her Majesty Revenue and Customs

\footnotetext{
${ }^{14}$ Ex post there is court enforcement, see also Footnote 5.
} 
(INTM541010) describes their rationale: "Thin capitalization commonly arises where a company is funded...by a third party...but with guarantees...provided to the lender by another group company... The effect of funding a .. company.. with excessive ... guaranteed debt is...excessive interest deductions. It is the possibility of excessive deductions for interest which the ...legislation on thin capitalization seeks to counteract." The similarity between this description and the characterization in the third column of Table 1 is striking, where the three ingredients (low equity value and high tax savings in the subsidiary along with high transfers from the parent) are visible. TC rules directly cap interest deductions or constrain debt/equity ratios below a certain level. Theorem 4 characterizes the optimal capital structure and ownership following the introduction of TC rules, also in combination with IDT. Then, Theorem 5 compares such connected units, subject to group specific taxes, with the stand alone organization.

Let us denote with $\left(F_{S}^{* *}, F_{P}^{* *}, \omega^{* *}\right)$ the solution to our optimization program when subsidiary debt does not exceed the cap $K$.

\section{Theorem 4. IDT and TC.}

Let there be bailouts, and let the debt constraint in the guaranteed unit be binding and equal to $K$ and let $0<\underline{\tau}_{D}<1$. Then, there exists a cap $\bar{K}$ such that, for every $K \leq \bar{K}$ :

i) the parent has optimal positive leverage $\left(F_{P}^{* *}>0\right)$;

ii) optimal subsidiary ownership is partial $\left(\omega^{* *}<1\right)$ if $\tau_{D}>\underline{\tau}_{D}$, full $\left(\omega^{* *}=1\right)$ if $\tau_{D} \leq \underline{\tau}_{D}$.

iii) when $\tau_{D}<\underline{\tau}_{D}$, parent debt $F_{P}^{* *}$ exceeds the comparable stand alone level of debt, $F_{S A}^{P *}$, if the ratio of parent to subsidiary default cost rate exceeds a constant $C$.

The first part of the theorem shows that TC rules break ownership irrelevance, because zero-leverage is never optimal for the parent unit. The forced reduction in subsidiary debt induces debt shifting onto the formerly zero-leverage parent, because increased tax savings in the parent must substitute for the forced reduction in subsidiary tax savings. As a consequence, partial subsidiary ownership no longer depends on specific ranges of the parent corporate income tax rate, as in the previous theorem. Finally, the third part of the theorem builds on the tension between the bailout guarantee on one side and the dividend transfer on the other. With larger debt, the parent saves larger cash flows from default when the 
dividend is sufficient to avoid insolvency. However, larger dividends are lost when they are insufficient. Moreover, subsidiary default costs increase due to the reduced bailout transfer. Such larger parent debt creates value when the default cost rate in the parent is sufficiently high relative to that of the subsidiary $\left(\frac{\alpha_{P}}{\alpha_{S}}>C\right)$.

Let us stress an important caveat. TC rules break ownership irrelevance, when $\tau_{P}<z$, only if the tax authority enforces TC rules in every guaranteed unit, including affiliates of horizontal groups. If it limits enforcement to proper subsidiaries in hierarchical groups, as it is often the case in practice, any hierarchical group would transform into a horizontal group to avoid TC constraints. ${ }^{15}$ Thus, TC rules are irrelevant for leverage and default. This result echoes IDT irrelevance in Lemma 2i), stated in the Appendix.

Table 3 exemplifies the results of Theorem 4, following the calibration in Leland (2007). It also permits an assessment of other non-obvious effects of tax combinations.

\begin{tabular}{|c|c|c|c|c|}
\hline \multicolumn{5}{|c|}{ Table 3: Group-Specific Taxes and Ownership Mutations } \\
\hline & No Thin Cap & \multicolumn{3}{|c|}{ Thin Cap, $F_{S}^{* *}=F_{S A}^{S *}$} \\
\hline & $\tau_{D}=0 \%$ & $\tau_{D}=0 \%$ & $\tau_{D}=1 \%$ & $\tau_{D}=7 \%$ \\
\hline Ownership $(\omega)$ & any & $100 \%$ & $87 \%$ & $0 \%$ \\
Value $(\nu)$ & 166.59 & 163.88 & 163.51 & 163.36 \\
Face Value of Debt $(F)$ & $220(0 ; 220)$ & $138(81 ; 57)$ & $131(74 ; 57)$ & $112(55 ; 57)$ \\
Cum-Dividend Equity $(E)$ & $49.59(49.52 ; 0.07)$ & $99.36(60.17 ; 39.19)$ & $98.61(59.44 ; 39.17)$ & $78.92(39.80 ; 39.12)$ \\
Default costs $(C)$ & $8.13(0 ; 8.13)$ & $1.56(1.12 ; 0.44)$ & $1.23(0.85 ; 0.38)$ & $1.02(0.78 ; 0.24)$ \\
Tax Burden $(T)$ & $25.40(20.01 ; 5.39)$ & $34.69(16.85 ; 17.84)$ & $35.35(17.18 ; 18.17)$ & $35.57(17.81 ; 17.76)$ \\
Dividend Tax $(I D T)$ & 0 & 0 & 0.30 & 0 \\
\hline
\end{tabular}

Table 3: This table reports the optimal ownership, value, debt, default costs, tax burden and dividend tax levied with different levels of dividend taxation, $\tau_{D}$, without and with TC rules. Figures of the parent and subsidiary unit, respectively, are reported in brackets. Cash flows are jointly normally distributed with correlation $\rho=0.2$. Parameters are set according to Leland (2007): $\alpha_{S}=\alpha_{P}=23 \%, \tau_{S}=\tau_{P}=20 \%$, $\phi=0.78, \sigma_{S}=\sigma_{P}=0.22, X_{0}^{S}=X_{0}^{P}=100, T=5$.

In the first column, both TC rules and IDT are absent. The subsidiary displays "Thin Capitalization", i.e. it has negligible equity capital (0.07), high debt (220) and default costs (8.13), along with a lower tax burden (5.39) than its zero-leverage parent (20.1). When TC rules constrain subsidiary debt to the stand alone level (as in the second to fourth columns), the tax burden of the subsidiary more than triples. Absent IDT, some debt shifts to the parent in order to contain the increase in the tax burden (that reaches $36.5 \%$ ). The parent

\footnotetext{
${ }^{15}$ This observation explains the reason why the UK regulator specifically considers any guaranteed affiliate to be subject to TC rules.
} 
now fully owns the equity in the subsidiary, thereby containing its own default costs. When IDT adds to TC, it takes a modest $1 \%$ tax rate to trigger a transformation of the fully owned hierarchical group into a pyramid (87\%) while a $7 \%$ rate, consistent with the lowest rate in the U.S. tax code, is sufficient to dismantle it. Optimal parent leverage decreases in the dividend tax rate, together with overall value. Default costs are dramatically lower than in the case without TC ( $\$ 8.13$ vs. values ranging from $\$ 1.02$ to $\$ 1.56$, depending on the IDT rate). Interestingly, they are also decreasing in the dividend tax rate: IDT, combined with TC, contain the distortion generated by the tax shield without hampering the role of bailouts.

Despite the reduction in debt and value, due to regulation, connected units in Table 3 always show higher value than stand-alone organizations. Moreover, they may combine private optimality (higher value) with a lower level of expected default costs relative to the competing stand alone organization. The following proposition addresses this possibility.

\section{Theorem 5. Group vs. Stand Alone Units: IDT and TC.}

Let there be bailouts, let the debt constraint in the guaranteed unit be binding at the stand alone level, $F_{S}^{* *}=F_{S A}^{S *}$, and $\tau_{D}>\bar{\tau}_{D}$. Then, the group displays both lower overall debt and default costs than the stand alone organization as well as higher value, despite group-specific regulation.

The theorem states that a proper combination of TC rules and IDT may generate groups with lower leverage and yet higher value than stand alone organizations. Such higher value stems from lower default costs since tax savings increase in debt. The intuition for the proof is as follows. When the IDT tax rate exceeds the upper threshold, the parent does not own the subsidiary and therefore receives no dividends. The relevant link between the units remains the bail out of the subsidiary, which increases value by reducing the default probability. To increase this bailout transfer, the parent optimally maintains lower leverage than it would as a stand alone firm.

The analysis we have carried out so far implies a rich variety of capital structures despite equal tax rates, bankruptcy cost rates and cash flows distributions. While connected units usually have higher debt and lower tax burdens than stand alone units, the last theorem 
indicates that we might actually observe regulated cases displaying lower leverage, higher tax burden and lower default costs. Our positive analysis therefore adds to the insight in Morck (2005). IDT may be used to transform a hierarchical group into a horizontal group, generating lower default costs. This result is perhaps not surprising, as second best economics predicts that two distortions may increase welfare. The following section shows that IDT may however increase default costs despite lowering group debt.

\subsection{The Volcker Rule and IDT}

Prudential rules proposed by the Volcker Rule and the Vickers Committee limit the possibility for banking units to bail out their SPVs (see Segura, 2017). Our Theorem 1 determines the effects of such a ban on ownership and leverage, when there are only income taxes. This section first highlights the impact of a bailout ban on default costs. It then analyzes the interplay of such prudential rules with the generalized tax-bankruptcy tradeoff.

Table 4 portrays group structure for the same parameters as Table 1. A bail out ban reduces overall debt and default costs at the same time increasing the tax burden (first and third columns), leaving them unchanged only when bailouts are zero in the unconstrained case (second column). As for capital structure, we know from Theorem 1 that it never pays to concentrate leverage in the subsidiary, absent bailouts. As a consequence, the parent company now raises positive debt in the third column and fully owns its subsidiary using dividend receipts to avoid its own default.

Moreover, the parent has higher optimal debt than its stand alone counterpart in the second and third columns suggesting that condition (B.9) in the Appendix holds. Unreported simulations show that for tax rates in a range $(0.16-0.26)$, such that the objective remains convex when other parameters are the baseline ones, condition (B.9) holds. Violations are likelier the lower is cash flow correlation, as suggested by Theorem 1, because the subsidiary more often transfers dividends when the parent defaults. Violations are also likelier the higher are both the tax differential, $\left|\tau_{P}-\tau_{S}\right|$, and cash flow volatility, implying higher parent debt and extreme cash flow realizations. Thus, when the parent tax rate is equal to $26 \%$, condition (B.9) does not hold for any subsidiary tax rate provided that volatility is 


\begin{tabular}{|c|c|c|c|}
\hline \multicolumn{4}{|c|}{ Table 4: No Bailout } \\
\hline & $\tau_{P}=26 \%, \sigma=44 \%$ & $\tau_{P}=26 \%, \sigma=22 \%$ & $\tau_{P}=20 \%, \sigma=22 \%$ \\
\hline Value $(\nu)$ & $164.93(132.21 ; 32.72)$ & $160.52(159.74 ; 0.78)$ & $165.14(162.80 ; 2.34)$ \\
\hline Ownership share $(\omega)$ & $100 \%$ & $100 \%$ & $100 \%$ \\
\hline Face Value of Debt $(F)$ & $151(100 ; 51)$ & $159(158 ; 1)$ & $159(156 ; 3)$ \\
\hline Debt Value $(D)$ & $110.48(77.76 ; 32.72)$ & $123.70(122.92 ; 0.78)$ & $124.04(121.70 ; 2.34)$ \\
\hline Cum-Dividend Equity Value $(E)$ & $106.22(54.44 ; 51.78)$ & $116.12(36.82 ; 79.30)$ & $118.91(41.10 ; 77.81)$ \\
\hline Default Costs $(C)$ & $2.62(1.76 ; 0.86)$ & $0.78(0.78 ; 0)$ & $0.56(0.56 ; 0)$ \\
\hline Tax Burden $(T)$ & $40.92(22.75 ; 18.17)$ & $38.95(18.97 ; 19.98)$ & $34.62(14.71 ; 19.91)$ \\
\hline Dividend Transfer $(I D)$ & 51.78 & 79.30 & 77.81 \\
\hline Value of SA units & $164.91(80.07 ; 84.84)$ & $158.52(77.05 ; 81.47)$ & $162.94(81.47 ; 81.47)$ \\
\hline Face Value of debt of SA units & $199(116 ; 83)$ & $117(60 ; 57)$ & $114(57 ; 57)$ \\
\hline Dividend Lost in Parent Default & $2.30 \%$ & $1.65 \%$ & $1.23 \%$ \\
\hline
\end{tabular}

Table 4: This table displays the optimal group structure with different parametric combinations, when bailouts are absent. Parameters are the same used in Table 1.

twice as large as the benchmark case and cash flow correlation is low enough (as in the first column of Table 4).

A ban on bailouts appears as a substitute to TC rules, in the sense that both rules break ownership irrelevance, increasing subsidiary capitalization and tax burden. However, the combination of IDT with the ban on bailouts has the following distinct effects. Table 5 displays such effects, as the IDT rate increases, with the same parametrization used in Table 3 in the previous section. With a zero IDT rate, a ban on bailouts causes a reduction in the subsidiary debt, from 220 in the unrestricted case (see the first column of Table 3) to 42. At the same time, there is debt shifting towards the parent unit, from zero up to 94 . Thus the Volcker Rule reduces both group debt (from 220 to 136) and default costs (from $8.13 \%$ to $1.67 \%$ of cash flows).

\begin{tabular}{|c|c|c|c|}
\hline \multicolumn{4}{|c|}{ Table 5: Effects of IDT on ownership and leverage, no bailouts } \\
\hline & $\tau_{D}=0 \%$ & $\tau_{D}=1 \%$ & $\tau_{D}=7 \%$ \\
\hline Ownership $(\omega)$ & $100 \%$ & $90 \%$ & $0 \%$ \\
Value $(\nu)$ & 163.67 & 163.20 & 162.94 \\
Face Value of Debt $(F)$ & $136(94 ; 42)$ & $137(86 ; 51)$ & $114(57 ; 57)$ \\
Cum-Dividend Equity $(E)$ & $110.92(61.49 ; 49.43)$ & $99.84(56.57 ; 43.27)$ & $78.64(39.32 ; 39.32)$ \\
Default Costs $(C)$ & $1.67(1.36 ; 0.31)$ & $1.89(1.29 ; 0.60)$ & $1.78(0.89 ; 0.89)$ \\
Tax Burden $(T)$ & $34.77(16.33 ; 18.44)$ & $34.98(16.62 ; 18.36)$ & $35.62(17.81 ; 17.81)$ \\
Dividend Tax $(I D T)$ & 0 & 0.35 & 0 \\
\hline
\end{tabular}

Table 5: This table reports the optimal ownership, value,debt, default costs, tax burden and dividend tax levied with different levels of dividend taxation, $\tau_{D}$, when bailouts are not allowed. Figures in brackets refer to the parent and the subsidiary unit, respectively. Cash flows are jointly Gaussian, with correlation $\rho=0.2$. The other parameters used in the analysis follow Leland (2007): $\alpha_{S}=\alpha_{P}=23 \%, \tau_{S}=\tau_{P}=20 \%, \phi=0.78$, $\sigma_{S}=\sigma_{P}=22 \%, X_{0}^{S}=X_{0}^{P}=100, T=5$. 
As the IDT tax rate increases to a modest level $\left(\tau_{D}=1 \%\right)$, parent ownership of the subsidiary drops to $90 \%$. While total debt is almost unchanged (137 vs. 136) and more balanced between the two units (86 in the parent, 51 in the subsidiary vs. 94 to 41), default costs increase markedly (1.89 vs. 1.67) because of the ban on bailouts. When $\tau_{D}$ further increases (to 7\%), as in the third column, optimal ownership of the subsidiary by the parent falls to zero. The (SPV) subsidiary is directly owned by the controlling party or sold to outside financiers. The two units never transfer funds internally and their optimal capital structure decisions coincide with those of stand alone firms. Default costs however increase, relative to the zero IDT rate case (1.78 vs. 1.67), even though the overall leverage is lower (114 vs. 136).

This analysis shows that IDT interfere with prudential regulation, that by itself eliminates the incentive to create a highly levered subsidiary SPV, containing default costs. The presence of IDT may increase default costs, contrary to the case of combinations with TC, by damaging the only remaining internal support channel - the one based on internal dividends. These last two results emphasize that financial stability outcomes depend on taxes, through not only the level of debt but internal ownership as well.

\subsection{Group Synergies and Tax Consolidation}

In the previous sections, group affiliation delivers financial synergies only. However, real synergies may also stem from, and motivate, internal ownership connections. They may ease investment choices (as in Stein, 1997 and Matvos and Seru, 2014) and labor reallocation (as in Cestone et al., 2017) or foster the interaction between product market competition and workers' incentives (as in Fulghieri and Sevilir, 2011). Another synergy enjoyed by groups is tax consolidation, by which a profitable parent can use subsidiary losses to reduce its taxable income, and viceversa. This section discusses the robustness of our results to such additional synergies, which may affect the predictions of our model in two respects. The first concerns both total leverage and the optimal wedge in the debt levels of the two units. The second regards the sensitivity of ownership to IDT.

At first glance, the presence of a real synergy may provide scope for higher leverage by enhancing group profitability in states of joint survival. However, such synergy also 
increases the cost of the selective default, as the surviving unit is no longer able to exploit it. This discourages debt differences, reducing the sensitivity of debt to the tax rate of each individual unit, thereby containing the overall debt level as well. The above argument applies to synergies that increase performance in good states. The possibility to transfer workers from the unit in default to the unit in operation, described in Cestone et al. (2017), is instead an example of a synergy reducing the costs of selective default in bad states. This insurance-like synergy may increase the wedge in the optimal leverage of the two units. The net effect of a real synergy on leverage is therefore not obvious, depending on the prevailing type.

The second effect of a real synergy is to reduce the responsiveness of ownership to IDT. However, such slower response appears only if the ownership transformation from a hierarchical to a horizontal group reduces the synergy benefits.

As for tax consolidation, this is an option for the connected units to jointly file for taxes. Sometimes the option is conditional on ownership exceeding a threshold, $1>\bar{\omega}>0$. ${ }^{16}$ Such option is valuable, because it implies that the tax burden of the group never exceeds the one of stand alone units, and is typically smaller. However, a trade-off, involving the choice of leverage, may emerge between the optimization of consolidation gains on the one hand and that of tax shield gains on the other.

The ownership irrelevance result of Theorem 2i) should hold for a sufficiently high cash flow correlation between the units, because the tax shield option is more valuable, relative to the consolidation option, the higher is correlation. For low correlation levels, the case of ownership irrelevance is less likely to hold and may disappear: the minimum optimal internal ownership is at least equal to the prescribed ownership threshold for consolidation, $\bar{\omega}>0$, in order to trigger consolidation gains on top of the tax shield optimization. The introduction of IDT impacts on the consolidation vs. tax shield trade-off. Increasing ownership up to the prescribed threshold, $\bar{\omega}$, lowers the tax burden through consolidation on the one hand, but increases taxes paid on intercorporate dividends on the other. Given a high $\tau_{P}$, the presence

\footnotetext{
${ }^{16}$ Consolidation is an option at the Federal level in the US and in other EU jurisdictions, such as France, Italy and Spain, provided internal ownership exceeds some predetermined threshold. The latter is lower for SPVs in the US. It is forbidden in certain jurisdictions, such as the UK and some US states.
} 
of consolidation synergies implies that internal ownership drops below $100 \%$ for a higher cut-off level of the IDT tax rate in Theorem 3ii). At the consolidation threshold, $\bar{\omega}$, it takes a discontinuous increase in the IDT tax rate to dismantle the hierarchical group.

The above reasoning takes the 2-unit structure as given. However, the controlling entity may be able to avoid the trade-off by setting up separate vehicles, characterized by a low tax rate $\tau_{P}$, that sell cash flow rights to outsiders and optimize the tax shield, while the rest of the group exploits consolidation. In this case, the analysis in the previous sections holds for these separate "tax arbitrage vehicles".

With these caveat in mind, the following section will discuss the implications of our theory in the light of some stylized facts.

\section{Model Implications and Observations on Group Structure}

This section scans through some observed behavior of connected units, following the logic of our analysis. This logic highlights the use of internal resources, in a tax-bankruptcy perspective, without considering real synergies, the allocation of funds to competing investment

projects and the extraction of private benefits. It also highlights an array of group structures, with a prominent role for hierarchical groups with fully owned subsidiaries rather than pyramids.

The case of multinationals appears to fit this logic. Parent companies wholly-own the vast majority of their foreign subsidiaries in a sample of 634 major U.S. multinational firms. Almost 40 percent of firms are directly owned by their U.S. parent company. The remaining firms, comprising 33,051 foreign subsidiaries, are arranged into more complex ownership structures. Out of this total, 37 percent of subsidiaries are part of hierarchical structures. Various tax considerations are an important factor in structuring affiliate ownership (Lewellen and Robinson, 2013). This evidence documents the existence of an even richer set of ownership structures responding to a richer array of foreign tax considerations. Hierarchical groups are not special to multinationals. The investigation of 270,374 groups in 129 countries reveals that two thirds of the 1,519,588 affiliates are held domestically. US groups represent an exception, in that affiliates abroad represent almost half of the total (Altomonte and Rungi, 2013). 
The above evidence may be consistent with both parts of Theorem 2. However, Theorem 2ii) highlights that internal dividends help support parent companies. Such support may be the reason why continental European groups have larger debt in parent companies than in subsidiaries (Bianco and Nicodano, 2006) and display positive correlation between subsidiary dividends and the parent firms' debt (De Jong et al., 2012). These hierarchical groups are often not widely held (Bloch and Kremp, 1999; Faccio and Lang, 2002), as our results would suggest. The use of internal support to contain bankruptcy risk and enhance borrowing capacity is present in family groups around the world (Masulis et al., 2011). Group firms have higher mean dividend yield than non-group firms. The dividend difference with respect to non-group firms is higher for bottom than for apex firms. Group firms are also able to borrow more than their non-group peers. Within pyramidal groups, companies in the upper layers borrow more than companies at the bottom.

As far as valuation is concerned, Masulis et al. (2011) uncover lower equity value (Q) of group affiliates with respect to non-group peers in apex companies, where the separation of ownership from control is minimal, but not in bottom companies. This evidence is hard to reconcile with expropriation of minorities through pyramids. Our analysis may help explain this evidence, associating lower equity value of parent companies with the provision of bailout funds to other affiliates' lenders (as in Table 1, Column 3).

Our results show that only group-specific tax provisions make partial or zero subsidiary ownership optimal (see Corollary 1). Masulis et al. (2011) document that the percentage of both family groups and family pyramids in a cross-section of countries is negatively related to an index of intra-group tax provisions, including Thin Capitalization rules, that measures the stringency of tax laws concerning to intra-group transactions. Kandel et al. (2015) recall that, in the 1930s and 1940s, pyramids were pervasive in the U.S.. The controlling entities, both families and widely held companies, flattened out their groups in response to the introduction of IDT, although some kept their layers by exploiting the exemptions granted to large ownership stakes. Currently, direct control via a horizontal structure is a common form of family ownership, although 80 percent of the firms preserve some indirect ownership through trusts, foundations, corporations and limited partnership (Villalonga and 
Amit, 2009). ${ }^{17}$

Our model indicates that intercorporate links allow the group to better exploit the tradeoff between lower tax burden and higher default costs, when interest deductions distort debt incentives, as documented by Desai et al. (2004). Another implication of our model, that emerges in the sample of multinational companies studied by Brok (2016), is that a change in the tax rate of one affiliate has nonlinear effects on total group debt. As far as TC rules are concerned, our model implies debt shifting onto the parent company when TC rules are strictly enforced on subsidiaries. Blouin et al. (2014) find that foreign affiliates' leverage responds to the introduction of TC rules in U.S. multinationals. However, the ratio of debt to assets of the consolidated worldwide firm does not react to the introduction of TC rules. This observation suggests that the multinational firm engages in debt shifting towards other group affiliates.

Our results (Theorem 2 part i)) imply that indifference between full, partial or zero subsidiary ownership is likely to hold when $\tau_{P}=\tau_{S}$ and there is no double taxation of dividends. This case of ownership irrelevance well represents financial conduits. Conduits are structured to be tax neutral, that is to avoid double taxation. ${ }^{18}$ Consistent with ownership irrelevance, conduits appear to be incorporated at times as proper subsidiaries with positive parent ownership, in other instances as orphan Special Purpose Vehicles with zero parent ownership (Gorton and Souleles, 2006). Consistent with the presumption that conduits reduce the overall tax burden, Han et al. (2015) show that securitization increases with the corporate tax rate, i.e., with incentives to exploit the tax shield. A reduction of the tax burden is possible in our model because the conduit-subsidiary deducts interest from taxes while enjoying support from its parent. In securitization, as Peaslee and Nirenberg (2001, ch.3) report, the SPV issues securities classified as debt instruments, with tax-deductible interests, depending on the type of transaction between the sponsor-parent and the SPV.

\footnotetext{
${ }^{17}$ Cooper et al. (2015) document a more recent ownership adjustment with a tax motivation. US business income migrates away from traditional corporations, with a $31.6 \%$ average tax rate, into pass-through partnerships, with a $15.9 \%$ rate.

${ }^{18}$ Tax neutrality applied as long as the Internal Revenue Service did not classify the SPV as a corporation. This would be the case if the SPV engaged in some active business beside passively administering the proceeds from its asset pool; and/or if it had multiple ownership classes without enjoying a REMIC (Real Estate Mortgage Investment Conduit) status (see Peaslee and Nirenberg, 2001, ch. 4 and 5).
} 
Moreover, there is a mechanism akin to a bailout transfer: the sponsoring unit and the investors agree upon the state contingent subsidization of the vehicle, beyond the formal obligations of the sponsor (Gorton and Souleles, 2006).

Private equity funds are also pass-through entities for U.S. tax purposes. As a result, the entity's income, gains, losses, deductions and credits are passed through to the partners and taxed only once at the investor level, avoiding the double taxation of profits. Funds are usually formed as Delaware limited partnerships or limited liability companies. ${ }^{19}$ This allows to classify membership interests into different classes (like common and preferred stock) with different rights and preferences. Distributions do not need to be proportionate to ownership and they can be specified in the agreement along with liquidation and voting preferences. Private equity funds, investing outside of the US, are often formed in jurisdictions with favorable tax regimes (Naidech, 2011). Target companies in going-private buyout transactions are highly levered throughout the merger waves (Guo et al., 2011). This private equity fund with its levered LBO firms echoes the low-tax zero-leverage parent that owns, with indefinite ownership interest, its levered subsidiary in our model. ${ }^{20}$ Additionally, the private equity fund participates in the restructurings of the firm via a state-contingent support mechanism, i.e. when it is insolvent, but profitable. Leverage in LBO firms thus contributes to tax savings and value creation (Acharya et al., 2013; Kaplan, 1989) along with efficiency gains (see Axelson et al., 2009), that are absent in our set up.

As for capital structure, our model provides a candidate explanation for some puzzling evidence that appears at odds with the traditional trade-off theory. First, it shows that dividend-paying subsidiaries may have zero optimal leverage, beside the parent companies in Luciano and Nicodano (2014) that might pay zero dividends. For instance, in the second column of Table 1 the (almost) zero leverage subsidiary supports its parent company, displaying also comparatively higher dividends, market value (to book value) of equity and tax burden than its proxy positive-leverage subsidiaries in Columns 1 and 3. These characteristics match the ones of dividend-paying zero leverage and almost zero-leverage firms in

\footnotetext{
${ }^{19}$ Scholes and Wolfson (1990) discuss the tax-disadvantage of the S-corporate form relative to the partnership form after the 1986 Tax Reform Act.

${ }^{20}$ In particular, Condition (B.10) in the Appendix is satisfied for any tax rate, as $G(0)=0$ when the parent is a fund.
} 
Strebulaev and Yang (2013). Last but not least, our theory may explain the heterogeneity in the capital structure choices of companies with the same tax-bankruptcy parameters, first observed in the U.S. by Bernanke et al. (1990). The logic of the model is that capital structure in a given firm depends not only on its own tax-bankruptcy parameters, but on the transfers to and from (possibly unlisted) connected units as well. ${ }^{21}$

\section{Summary and Concluding Comments}

This paper determines the ownership structure of two units under common control, abandoning the textbook fiction of the stand alone firm. It elaborates on the idea that internal ownership helps support upstream units, while limited liability preserves them from contagion. This idea also leads to new insights on the relationship between between tax rates and debt, between support and default costs, between value and diversification, between debt and non-debt tax shields.

Our results show how tax provisions generate the variety of ownership structures of connected units that we commonly observe. Hierarchical organizations with fully owned subsidiaries are optimal when the parent tax rate is sufficiently high, as they can exploit both bailouts and internal dividends as supporting mechanisms. Any ownership structure may instead emerge, when the tax rate of the supporting unit is small, leading to an unbalanced capital structure, with debt concentrated in the supported unit. A small tax rate reminds of tax arbitrage vehicles, that reduce their effective tax rate through either non-debt tax shields or incorporation in low tax jurisdictions. The endogenous interest spread plays a crucial role, together with bailouts, in generating ownership irrelevance. It is the positive feedback from higher default costs to higher tax savings that leads to a zero leverage parent.

Our model also embeds group specific provisions in the tax-bankruptcy trade-off analysis, extending it beyond income taxes. The presence of IDT discourages direct ownership, and either pyramids or horizontal groups may become value maximizing. TC rules, if applying to proper subsidiaries only, do not contain leverage in tax arbitrage vehicles, that can change their ownership structure to preserve tax savings. On the contrary, they are effective if

\footnotetext{
${ }^{21}$ This reminds the logic underlying the study of Faulkender and Smith (2014).
} 
they apply to all guaranteed affiliates. No bailout rules appear as substitutes to TC rules, as they contain both tax savings and default costs. However, IDT may interfere with this prudential rule and increase default costs by limiting the only remaining internal support mechanism. In a nutshell, we highlight the tax-bankruptcy motives of complex structures, leaving aside real synergies, contractual incompleteness, agency problems and inter-temporal issues stressed in prior capital structure literature.

Our structural analysis implies that the observed heterogeneity in the capital structure choices of listed companies with the same tax bankruptcy parameters depends on the transfers to and from (possibly unlisted) connected units. It therefore suggests an agenda for future empirical work, jointly considering capital and ownership structure. 


\section{Appendix A. Definition of the $h(\cdot)$ and $k(\cdot)$ functions}

The function $h\left(X_{S}\right)$ defines the set of states of the world in which the parent company has enough funds to intervene in saving its affiliate from default while at the same time remaining solvent. The rescue happens if the cash flows of the parent $X_{P}$ are enough to cover both the obligations of the parent and the remaining part of those of the subsidiary. The function $h\left(X_{S}\right)$, which defines the level of parent cash flows above which the rescue occurs, is defined in terms of the cash flows of the subsidiary as:

$$
h\left(X_{S}\right)= \begin{cases}X_{P}^{d}+\frac{F_{S}}{1-\tau_{S}}-\frac{X_{S}}{1-\tau_{S}} & X_{S}<X_{S}^{Z}, \\ X_{P}^{d}+X_{S}^{d}-X_{S} & X_{S} \geq X_{S}^{Z} .\end{cases}
$$

Similarly, the function $k\left(X_{P}\right)$, which describes the level of dividends required to rescue the parent from default, is defined as

$$
k\left(X_{P}\right)= \begin{cases}X_{S}^{d}+\frac{F_{P}-X_{P}}{\omega\left(1-\tau_{S}\right)\left(1-\tau_{D}\right)} & X_{P}<X_{P}^{Z}, \\ X_{S}^{d}+\frac{F_{P}-\tau_{P} X_{P}^{Z}-\left(1-\tau_{P}\right) X_{P}}{\omega\left(1-\tau_{D}\right)\left(1-\tau_{S}\right)} & X_{P} \geq X_{P}^{Z} .\end{cases}
$$

When $X_{S}<X_{S}^{Z}\left(X_{P}<X_{P}^{Z}\right)$ the cash flow $X_{S}\left(X_{P}\right)$ of the subsidiary does not give rise to any tax payment, as it is below the tax shield generated in that unit.

\section{Appendix B. Proofs}

Proof that a stand alone firm has positive leverage $\left(F_{S A}^{*}>0\right)$ when $\phi=1$.

First of all, let us suppress both the i superscript and the subscripts SA and i for notational simplicity. The derivative of debt $D$ with respect to $F$ for a stand alone unit is

$$
\frac{d D}{d F}=\phi\left[-\alpha \frac{d X^{d}}{d F} X^{d} f\left(X^{d}\right)+\tau \frac{d X^{Z}}{d F}\left(G\left(X^{d}\right)-G\left(X^{Z}\right)\right)+1-G\left(X^{d}\right)\right] .
$$

When $F=0$, it follows that

$$
\frac{d D(0)}{d F}=\phi(1-G(0))
$$


The derivative of the tax shield $X^{Z}$ in $F$ is $d X^{Z} / d F=1-\frac{d D}{d F}$, while that of the default threshold $X^{d}$ is $d X^{d} / d F=1+\frac{\tau}{1-\tau} \frac{d D}{d F}$.

Default costs are non-decreasing in $\mathrm{F}$, since $\frac{d C}{d F}=\alpha X^{d} f\left(X^{d}\right) \frac{d X^{d}}{d F} \phi$. This derivative is 0 when $F=0$. The tax burden is decreasing in $\mathrm{F}: \frac{d T}{d F}=-\tau \phi \frac{d X^{Z}}{d F}\left(1-G\left(X^{Z}\right)\right)$.

It follows that the sum of taxes and default costs is always non-increasing in $F$ at $F=0$ when $\phi=1$ :

$$
\frac{d T(0)}{d F}+\frac{d C(0)}{d F}=-\tau G(0)(1-G(0)) \leq 0
$$

and it is strictly decreasing unless $G(0)=1$ or $G(0)=0$, i.e. the firm is never profitable or always profitable, respectively. When $0<G(0)<1$, then, the Kuhn-Tucker conditions of the minimum program for a stand alone unit are violated at $F=0$. Such conditions are indeed:

$$
\left\{\begin{array}{l}
\frac{d T(F)}{d F}+\frac{d C(F)}{d F}=\lambda \\
\lambda F=0 \\
\lambda \geq 0
\end{array}\right.
$$

When $F=0, \lambda \geq 0$ and condition (i) is violated, since its l.h.s., when $\phi=1$, is strictly negative, as equation (B.2) shows.

Kuhn-Tucker conditions of the minimum program (9)

For simplicity, we only report the dependence of the functions on the parent and subsidiary debt and the evaluation of the conditions at $\omega^{*}$, when necessary. 


$$
\begin{cases}\frac{d T_{S A}^{P}\left(F_{P}^{*}\right)}{d F_{P}}+\frac{d C_{S A}^{P}\left(F_{P}^{*}\right)}{d F_{P}}-\frac{\partial \Gamma\left(F_{P}^{*}, F_{S}^{*}\right)}{\partial F_{P}}-\frac{\partial \Delta C\left(F_{P}^{*}, F_{S}^{*}\right)}{\partial F_{P}}+\frac{\partial \Delta T\left(F_{P}^{*}, F_{S}^{*}\right)}{\partial F_{P}}=\mu_{1}, & (i) \\ F_{P}^{*} \geq 0, & (i i) \\ \mu_{1} F_{P}^{*}=0, & (\text { iii }) \\ \frac{d T_{S A}^{S}\left(F_{S}^{*}\right)}{d F_{S}}+\frac{d C_{S A}^{S}\left(F_{S}^{*}\right)}{d F_{S}}-\frac{\partial \Gamma\left(F_{P}^{*}, F_{S}^{*}\right)}{\partial F_{S}}-\frac{\partial \Delta C\left(F_{P}^{*}, F_{S}^{*}\right)}{\partial F_{S}}+\frac{\partial \Delta T\left(F_{P}^{*}, F_{S}^{*}\right)}{\partial F_{S}}=\mu_{2}, & (i v) \\ F_{S}^{*} \geq 0, & (v) \\ \mu_{2} F_{S}^{*}=0, & (v i) \\ \mu_{1} \geq 0, \mu_{2} \geq 0 & (v i i) \\ -\frac{\partial \Delta C\left(F_{P}^{*}, F_{S}^{*}\right)}{\partial \omega}+\frac{\partial \Delta T\left(F_{P}^{*}, F_{S}^{*}\right)}{\partial \omega}=\mu_{3}+\mu_{4} & (\text { viii }) \\ \omega^{*}-1 \leq 0 & (\text { ix }) \\ \omega^{*} \geq 0 & (x) \\ \mu_{3}\left(\omega^{*}-1\right)=0 & (x i) \\ \mu_{4}\left(\omega^{*}\right)=0 & (x i i) \\ \mu_{3} \leq 0, \mu_{4} \geq 0 & (x i i i)\end{cases}
$$

Properties of $\Gamma, \Delta C, \Delta T$

Lemma 1. The default costs saved by the subsidiary, $\Gamma$, are non-increasing in parent debt. The default costs saved by the parent, $\Delta C$, are non-decreasing in internal ownership, and they are non-increasing in subsidiary debt. Both internal dividends and the additional tax burden, $\Delta T$, are non-increasing in the subsidiary debt, insensitive to parent debt, and non-decreasing in internal ownership. 
Proof. The integral expressions of $\Gamma, \Delta C$ and $\Delta T$ are:

$$
\begin{aligned}
\Gamma & =\alpha_{S} \int_{0}^{X_{S}^{d}} \int_{h\left(X_{S}\right)}^{+\infty} x g(x, y) d y d x \\
\Delta C & =\alpha_{P} \phi\left[\int_{0}^{X_{P}^{Z}} \int_{X_{S}^{d}+\frac{F_{P}-x}{\omega\left(1-\tau_{D}\right)\left(1-\tau_{S}\right)}}^{+\infty} x g(x, y) d y d x+\int_{X_{P}^{Z}}^{X_{P}^{d}} \int_{X_{S}^{d}+\frac{F_{P}-\tau_{P} X_{P}^{z}-\left(1-\tau_{P}\right) x}{\omega\left(1-\tau_{D}\right)\left(1-\tau_{S}\right)}}^{+\infty} x g(x, y) d y d x+\right. \\
& -\int_{0}^{X_{P}^{Z}} \int_{X_{S}^{d}}^{X_{S}^{d}+\frac{F_{P}}{\omega\left(1-\tau_{P}\right)\left(1-\tau_{S}\right)}} D I V\left(y, F_{S}\right) g(x, y) d y d x+ \\
& -\int_{X_{P}^{Z}}^{X_{P}^{d}} \int_{X_{S}^{d}}^{X_{S}^{d}+\frac{F_{P}-\tau_{P} X_{P}^{Z}-\left(1-\tau_{P}\right) x}{\omega\left(1-\tau_{D}\right)\left(1-\tau_{S}\right)}} D I V\left(y, F_{S}\right) g(x, y) d y d x+ \\
& \left.-\int_{-\infty}^{0} \int_{X_{S}^{d}}^{X_{S}^{d}+\frac{F_{P}}{\omega\left(1-\tau_{D}\right)\left(1-\tau_{S}\right)}} D I V\left(y, F_{S}\right) g(x, y) d y d x\right] \\
\Delta T & \left.=\phi \omega \tau_{D} \int_{X_{S}^{d}}^{+\infty}\left[\left(1-\tau_{S}\right) x+\tau_{S} X_{S}^{Z}-F_{S}\right)\right] f(x) d x
\end{aligned}
$$

where $D I V\left(y ; F_{S}\right)=\omega\left(1-\tau_{D}\right)\left[\left(1-\tau_{S}\right) y+\tau_{S} X_{S}^{Z}-F_{S}\right]$.

We now compute the relevant derivatives, and we prove our statement:

$$
\frac{\partial \Gamma}{\partial F_{P}}=-\alpha_{S} \phi \frac{\partial X_{P}^{d}}{\partial F_{P}}\left[\int_{0}^{X_{S}^{Z}} x g\left(x, X_{P}^{d}+\frac{F_{S}}{1-\tau_{S}}-\frac{x}{1-\tau_{S}}\right) d x+\int_{X_{S}^{Z}}^{X_{S}^{d}} x g\left(x, X_{P}^{d}+X_{S}^{d}-x\right) d x\right] \leq 0,
$$




$$
\begin{aligned}
\frac{\partial \Delta C}{\partial F_{P}} & =\alpha_{P} \phi\left[\frac{\partial X_{P}^{d}}{\partial F_{P}} \int_{X_{S}^{d}}^{+\infty} X_{P}^{d} g\left(X_{P}^{d}, y\right) d y+\right. \\
& -\int_{-\infty}^{X_{P}^{Z}} \frac{F_{P}}{\omega\left(1-\tau_{D}\right)\left(1-\tau_{S}\right)} g\left(x, X_{S}^{d}+\frac{F_{P}-x^{+}}{\omega\left(1-\tau_{D}\right)\left(1-\tau_{S}\right)}\right) d x+ \\
& \left.-\int_{X_{P}^{Z}}^{X_{P}^{d}}\left[\frac{1-\tau_{P} \frac{\partial X_{P}^{Z}}{\partial F_{P}}}{\omega\left(1-\tau_{D}\right)\left(1-\tau_{S}\right)}\right]\left(F_{P}+\tau_{P}\left(x-X_{P}^{Z}\right)\right) g\left(x, X_{S}^{d}+\frac{F_{P}-\tau_{P} X_{P}^{Z}-\left(1-\tau_{P}\right) x}{\omega\left(1-\tau_{D}\right)\left(1-\tau_{S}\right)}\right) d x\right] \\
\frac{\partial \Delta C}{\partial F_{S}} & =-\alpha_{P} \phi\left[\frac{\partial X_{S}^{d}}{\partial F_{S}} \int_{0}^{X_{P}^{Z}} F_{P} g\left(x, X_{S}^{d}+\frac{F_{P}-x}{\omega\left(1-\tau_{D}\right)\left(1-\tau_{S}\right)}\right) d y+\right. \\
& +\int_{-\infty}^{X_{P}^{Z}} \int_{X_{S}^{d}}^{X_{S}^{d}+\frac{F_{P}-x^{+}}{\omega\left(1-\tau_{D}\right)\left(1-\tau_{S}\right)}}\left[\tau_{S} \frac{\partial X_{S}^{Z}}{\partial F_{S}}-1\right] g(x, y) d y d x+ \\
& +\frac{\partial X_{S}^{d}}{\partial F_{S}} \int_{X_{P}^{Z}}^{X_{P}^{d}}\left[F_{P}-\tau_{P} X_{P}^{Z}+\tau_{P} x\right] g\left(x, X_{S}^{d}+\frac{F_{P}-\tau_{P} X_{P}^{Z}-\left(1-\tau_{P}\right) x}{\omega\left(1-\tau_{D}\right)\left(1-\tau_{S}\right)}\right) d x+ \\
& \left.+\int_{X_{P}^{Z}}^{X_{P}^{d}} \int_{X_{S}^{d}}^{X_{S}^{d}+\frac{F_{P}-\tau_{P} X_{P}^{Z}-\left(1-\tau_{P}\right) x}{\omega\left(1-\tau_{D}\right)\left(1-\tau_{S}\right)}}\left[\tau_{S} \frac{\partial X_{S}^{Z}}{\partial F_{S}}-1\right] g(x, y) d y d x\right] \leq 0 \\
\frac{\partial \Delta T}{\partial F_{P}} & =0, \quad \phi \quad \mathrm{B} .6) \\
\frac{\partial \Delta T}{\partial F_{S}} & =\phi \omega \tau_{D}\left[\tau_{S} \frac{d X_{S}^{Z}}{d F_{S}}-1\right]\left(1-G\left(X_{S}^{d}\right)\right) \leq 0 .
\end{aligned}
$$

$$
\begin{aligned}
\frac{\partial \Delta C}{\partial \omega} & =\alpha_{P} \phi\left[\int_{-\infty}^{X_{P}^{Z}} F_{P} \frac{F_{P}-x^{+}}{\omega^{2}\left(1-\tau_{D}\right)\left(1-\tau_{S}\right)} g\left(x, X_{S}^{d}+\frac{F_{P}-x}{\omega\left(1-\tau_{D}\right)\left(1-\tau_{S}\right)}\right) d x+\right. \\
& +\int_{X_{P}^{Z}}^{X_{P}^{d}}\left[F_{P}-\tau_{P} X_{P}^{Z}+\tau_{P} x\right] \frac{F_{P}-\tau_{P} X_{P}^{Z}-\left(1-\tau_{P}\right) x}{\omega^{2}\left(1-\tau_{D}\right)\left(1-\tau_{S}\right)} g\left(x, X_{S}^{d}+\frac{F_{P}-\tau_{P} X_{P}^{Z}-\left(1-\tau_{P}\right) x}{\omega^{2}\left(1-\tau_{D}\right)\left(1-\tau_{S}\right)}\right) d x+ \\
& -\int_{-\infty}^{X_{P}^{Z}} \int_{X_{S}^{d}}^{X_{S}^{d}+\frac{F_{P}-x^{+}}{\omega\left(1-\tau_{D}\right)\left(1-\tau_{S}\right)}} \frac{D I V\left(y, F_{S}\right)}{\omega} g(x, y) d y d x+ \\
& \left.-\int_{X_{P}^{Z}}^{X_{P}^{d}} \int_{X_{S}^{d}}^{X_{S}^{d}+\frac{F_{P}-\tau_{P} X_{P}^{Z}-\left(1-\tau_{P}\right) x}{\omega\left(1-\tau_{D}\right)\left(1-\tau_{S}\right)}} \frac{D I V\left(y, F_{S}\right)}{\omega} g(x, y) d y d x\right] \geq 0 .
\end{aligned}
$$

$\frac{\partial \Delta C}{\partial \omega} \geq 0$ descends from our assumptions of convexity on the objective function and a uni-modal the marginal density $f$. In such case, default costs saved in the parent through dividends do not fall when the dividend transfer from the subsidiary increase. The change in the tax burden due to IDT is always non-decreasing in $\omega$ as well, as - ceteris paribus - 
higher dividend taxes are paid when the ownership share is higher:

$$
\frac{\partial \Delta T}{\partial \omega}=\phi \tau_{D} \int_{X_{S}^{d}}^{+\infty}\left(x\left(1-\tau_{S}\right)+\tau_{S} X_{S}^{Z}-F_{S}\right) f(x) d x \geq 0
$$

This derivative has value zero when $\tau_{D}=0$.

\section{Proof of Theorem 1.}

Let us analyze the Kuhn-Tucker condition (i) when the bailout is absent and thus $\frac{\partial \Gamma}{\partial F_{P}}=0$. The condition is violated for every $F_{S}$, when evaluated at $F_{P}=0$. Indeed, $\frac{\partial T_{S A}^{P}(0)}{\partial F_{P}}+\frac{\partial C_{S A}^{P}(0)}{\partial F_{P}}<$ 0 , because of convexity of the stand alone problem. The two remaining terms appearing in the 1.h.s. are zero when $F_{P}=0$ and $\tau_{D}=0$, as one can easily see from (B.5) and (B.6). As a consequence, condition (i) is never satisfied (the r.h.s. of the inequality being zero) and the parent optimally raises non-zero debt: $F_{P}^{*}>0$.

We now study the choice of optimal ownership when $F_{P}^{*}>0$. Let us first consider $\omega^{*}=0$, i.e. $\mu_{4} \geq 0$ and $\mu_{3}=0$. Condition (viii) is violated, since the l.h.s. is negative at $\omega=0$ from (B.7). Hence, zero ownership is not optimal. The existence of an interior solution, $0<\omega^{*}<1$, requires both $\mu_{3}=0$ and $\mu_{4}=0$. Condition (viii) is satisfied only for $\omega^{*} \rightarrow \infty$, which violates condition (ix). Hence, no interior solution satisfies the Kuhn-Tucker conditions. Finally, let us analyze the corner solution $\omega^{*}=1$, which requires $\mu_{3} \leq 0, \mu_{4}=0$. Condition (viii) is satisfied for an appropriate $\mu_{3}$ : all other conditions can be satisfied at $F_{S}^{*}, F_{P}^{*}, \omega^{*}=1$. It follows that $\omega^{*}=1$ when $\tau_{D}=0$. This proves the first part of the proposition.

Let us now turn to the second part of our proposition. It is sufficient, given our convexity assumption, and since $\Delta C$ is non-increasing in $F_{S}$, to show that $\frac{\partial \Delta C\left(F_{S A}^{P *}, F_{S A}^{S *}\right)}{\partial F_{P}}>0$. This rules out the possibility of a solution with $F_{P}^{*} \leq F_{S A}^{P *}$, as the Kuhn-Tucker condition (i) in (B.3) 
is never satisfied. Considering expression (B.5), such condition requires that

$$
\begin{array}{ll}
\alpha_{P} \quad \phi\left[\frac{\partial X_{P}^{d}}{\partial F_{P}} \int_{X_{S}^{d}}^{+\infty} X_{P}^{d} g\left(X_{P}^{d}, y\right) d y+\right. \\
-\quad \int_{-\infty}^{X_{P}^{Z}} \frac{F_{S A}^{P *}}{\left(1-\tau_{S}\right)} g\left(x, X_{S}^{d}+\frac{F_{S A}^{P *}-x^{+}}{\left(1-\tau_{S}\right)}\right) d x+ \\
\left.-\quad \int_{X_{P}^{Z}}^{X_{P}^{d}}\left[\frac{1-\tau_{P} \frac{\partial X_{P}^{Z}}{\partial F_{P}}}{\left(1-\tau_{S}\right)}\right]\left(F_{S A}^{P *}+\tau_{P}\left(x-X_{P}^{Z}\right)\right) g\left(x, X_{S}^{d}+\frac{F_{S A}^{P *}-\tau_{P} X_{P}^{Z}-\left(1-\tau_{P}\right) x}{\left(1-\tau_{S}\right)}\right) d x\right]>0
\end{array}
$$

where all the thresholds are evaluated at the stand alone debt levels $\left(F_{S A}^{P *}, F_{S A}^{S *}\right)$. Indeed, this condition requires that the marginal change in default costs saved due to an increase over parent debt above the optimal stand alone level is positive.

Let us turn to the last part of the theorem. Consider the case of equal debts, at the optimal level for the stand alone units. With perfect correlation, subsidiary dividends neither rescue the parent nor are lost in its default, since both affiliates are either solvent or defaulted in the same states of the world. This proves part (iii) and concludes our proof of the theorem.

Notice that, marginally increasing parent debt, while reducing debt in the subsidiary, leaves default costs unchanged and therefore tax savings. With slightly lower correlation, there will be instances where dividends rescue the parent when its cash flow is just below the parent default threshold and the subsidiary cash flow just above it. Since expected parent cash flows are larger than dividends, savings in default costs are positive, and condition (B.9) holds.

\section{Proof of Theorem 2}

Consider the Kuhn-Tucker conditions (i) to (xiii) in (B.3). Under our convexity assumption, these conditions are necessary and sufficient. We first investigate the existence of a solution in which $F_{P}^{*}=0$, holding $F_{S}>0$. If such a solution does not exist, then convexity implies the existence of another solution with $F_{P}^{*}>0$. After determining optimal capital structure, we turn to optimal ownership structure.

A solution for capital structure characterized by $F_{P}^{*}=0, F_{S}^{*}>0$ implies $\mu_{1} \geq 0$ and $\mu_{2}=0$. We focus on condition (iv) first. We have to prove that the term $-\frac{\partial \Delta C\left(F_{P}^{*}=0, F_{S}^{*}\right)}{\partial F_{S}}+$ 
$\frac{\partial \Delta T\left(F_{P}^{*}=0, F_{S}^{*}\right)}{\partial F_{S}}$ has a negative limit as subsidiary debt, $F_{S}$ tends to zero, and a positive limit when $F_{S}$ goes to infinity, since the rest of the l.h.s. does, under the technical assumptions that $x f(x)$ converges as $x \longrightarrow+\infty$ (see Luciano and Nicodano, 2014).

Note that $\frac{\partial \Delta C\left(0, F_{S}\right)}{\partial F_{S}}=0$ for every $F_{S}$, because this derivative measures the change in parent default costs associated with subsidiary dividends, when the parent has zero debt. Moreover, $\frac{\partial \Delta T}{\partial F_{S}}$ is always lower than or equal to zero, and has a negative limit as $F_{S}$ goes to zero, since $\lim _{F_{S} \longrightarrow 0} \frac{\partial X_{S}^{Z}}{\partial F_{S}}=1-\phi(1-G(0))>0$. When $F_{S}$ goes to infinity, $\frac{\partial \Delta T}{\partial F_{S}}$ goes to zero, as $G\left(X_{S}^{d}\right)$ tends to one. This proves that, when $F_{P}^{*}=0$, there exists an $F_{S}^{*}>0$, which solves the equation that equates the l.h.s. of condition (iv) to zero.

Let us now turn to condition (i). We recall that the derivative $\frac{\partial \Delta C}{\partial F_{P}}$ vanishes at $F_{P}^{*}=0$, see (B.5). Hence, we look for conditions such that the l.h.s. of condition (i) is positive and set it equal to $\mu_{1}$ to fulfill it. The l.h.s. of (i) is positive is

$$
\begin{array}{r}
\frac{\tau_{P}\left(1-\tau_{P}\right) G(0)(1-G(0))}{1-\tau_{P} G(0)} \leq \alpha_{S}\left[\int_{0}^{X_{S}^{Z}} x g\right. \\
\left(x, \frac{F_{S}}{1-\tau_{S}}-\frac{x}{1-\tau_{S}}\right) d x+ \\
\left.+\int_{X_{S}^{Z}}^{X_{S}^{d}} x g\left(x, X_{S}^{d}-x\right) d x\right]
\end{array}
$$

Under our convexity assumption, the r.h.s. is increasing in $F_{S}$. Hence, a sufficient condition for the existence of a zero-leverage parent is

$$
\begin{array}{r}
\frac{\tau_{P}\left(1-\tau_{P}\right) G(0)(1-G(0))}{1-\tau_{P} G(0)} \leq \alpha_{S}\left[\int_{0}^{X_{S A}^{S, Z *}} x g\left(x, \frac{F_{S A}^{S *}}{1-\tau_{S}}-\frac{x}{1-\tau_{S}}\right) d x+\right. \\
\left.+\int_{X_{S A}^{Z *}}^{X_{S A}^{S, d *}} x g\left(x, X_{S A}^{S, d *}-x\right) d x\right]
\end{array}
$$

where $G(0)$ is the cumulative probability of a (parent) cash-flow lower than or equal to zero, $F_{S A}^{S *}$ is the optimal debt of the stand alone counterpart of the subsidiary (i.e. that receives no bailout transfer from its parent and transfers no dividend to its parent) and $X_{S A}^{S, Z *}, X_{S A}^{S, d *}$ represent its optimal tax shield and default threshold, respectively. Both sides of this inequality are non-negative. The l.h.s. is increasing in $\tau_{P}$, while the r.h.s. is independent of $\tau_{P}$. Hence, for any fixed value of the r.h.s., there exists a low enough value of $\tau_{P}$ satisfying 
this condition. We define $z\left(\rho, \alpha_{S}, \alpha_{P}, \tau_{S}\right)$ as the cut-off value of the parent tax rate. Then $\tau_{P}<z$ is a sufficient condition for the existence of a solution in which $F_{P}^{*}=0$. Straightforward differentiation shows that $z\left(\rho, \alpha_{S}, \alpha_{P}, \tau_{S}\right)$ is independent of $\alpha_{P}$, increasing in $\tau_{S}$ and inversely u-shaped in $\alpha_{S}$.

The second result concerning capital structure contained in part (i) follows directly from Theorem 2 part 2) in Luciano and Nicodano (2014). The constant Q is equal to

$$
Q=\frac{\operatorname{Pr}\left(X_{S}>\bar{X}_{S}^{Z}\right) \frac{\partial \bar{X}_{S}^{Z}}{\partial F_{S}}}{\bar{X}_{S}^{d} \frac{\partial \bar{X}_{S}^{d}}{\partial F_{S}} \operatorname{Pr}\left(X_{S}=\bar{X}_{S}^{d}, X_{P}<0\right)+\frac{\partial h}{\partial F_{S}} \int_{0}^{\bar{X}_{S}^{d}} x g(x, h(x)) d x},
$$

where the notation $\operatorname{Pr}(Y)$ is used to refer to the probability of event $Y$ and $\bar{X}_{S}^{Z}$ and $\bar{X}_{S}^{d}$ are the no tax and default threshold respectively, evaluated at $F_{P}=0, F_{S}=F_{S A}^{P *}+F_{S A}^{S *}$.

We are now ready to turn to ownership, thereby completing the proof of part (i). When $\tau_{P} \leq z$, implying $F_{P}^{*}=0$, condition (viii) is satisfied for any $\omega$. The dividend from the subsidiary, $\omega$, has no effect on both the parent default costs $\left(\Delta C=0\right.$ because $F_{P}^{*}=0$, implying $\left.X_{P}^{d}=0\right)$ and the tax burden $\left(\Delta T=0\right.$ because $\tau_{D}=0$ by assumption). Hence $\omega$ has no effect on the value of the parent. Similarly, the tax burden of the subsidiary and its value are independent of $\omega$. It follows that $\omega^{*}$ is indefinite.

Let us now prove part (ii). Let us consider again the Kuhn-Tucker condition (i). This condition is not satisfied at $\left(F_{P}=0, F_{S}=F_{S}^{*}\right)$ when

$$
\begin{array}{r}
\frac{\tau_{P}\left(1-\tau_{P}\right) G(0)(1-G(0))}{1-\tau_{P} G(0)}>\alpha_{S}\left[\int_{0}^{X_{S}^{Z}} x g\left(x, \frac{F_{S}}{1-\tau_{S}}-\frac{x}{1-\tau_{S}}\right) d x+\right. \\
\left.+\int_{X_{S}^{Z}}^{X_{S}^{d}} x g\left(x, X_{S}^{d}-x\right) d x\right]
\end{array}
$$

We define the level of $\tau_{P}$ above which condition (B.12) is satisfied as $z^{\prime}$. Notice that $z^{\prime}>z$, since $F_{S}^{*} \geq F_{S A}^{*}$ when $F_{P}=0$. Then, when $\tau_{P}>z^{\prime}$, the parent optimally raises debt, as there exists no solution in which $F_{P}^{*}=0$. We consider now the choice of optimal ownership when $F_{P}^{*}>0$.

Let us first assume $\omega^{*}=0, \mu_{4} \geq 0$ and $\mu_{3}=0$. Condition (viii) is violated, since the l.h.s. is negative at $\omega=0$ from (B.7). Hence, zero ownership is not optimal. The existence of an 
interior solution, $0<\omega^{*}<1$, requires both $\mu_{3}=0$ and $\mu_{4}=0$. Condition (viii) is satisfied only for $\omega^{*} \rightarrow \infty$, which violates condition (ix). Hence, no interior solution satisfies the Kuhn-Tucker conditions. Finally, let us analyze the corner solution $\omega^{*}=1$, which requires $\mu_{3} \leq 0, \mu_{4}=0$. Condition (viii) is satisfied for an appropriate $\mu_{3}$ : all other conditions can be satisfied at $F_{S}^{*}, F_{P}^{*}, \omega^{*}=1$. It follows that $\omega^{*}=1$ when $\tau_{D}=0$; as such, part (ii) is proven.

\section{Proof of Theorem 3}

Before proving the theorem, let us state and prove the following lemma:

Lemma 2. Let the tax rate on intercorporate dividend be positive $\left(0<\tau_{D}<1\right)$. Then:

(i) if $\tau_{P} \leq z$, the optimal internal ownership is zero $\left(\omega^{*}=0\right)$;

(ii) if $\tau_{P} \geq z^{\prime}$, then there exists a $\underline{\tau}_{D}>0$ such that optimal internal ownership is less than full $\left(0 \leq \omega^{*}<1\right)$ if $\tau_{D}>\underline{\tau}_{D}$.

\section{Proof.}

(i) We first show that $F_{P}^{*}=0$ when $\tau_{P} \leq z$ and $\tau_{D}>0$. Let us denote with $F_{P}^{0}$ and $F_{S}^{0}$ the optimal values of $F_{P}$ and $F_{S}$ absent IDT. Consider the K-T conditions (i) and (iv). It can be proved that $\frac{\partial^{2} \Delta C}{\partial F_{P} \partial \tau_{D}}<0, \frac{\partial^{2} \Delta T}{\partial F_{P} \partial \tau_{D}}>0$, where the former is implied by convexity of the objective function. Focusing on the l.h.s. of condition (i), it is easy to conclude that $F_{P}^{*} \leq F_{P}^{0}$, when $\tau_{D}>0$. Indeed, the sum of the first two terms has to decrease to counterbalance when the last two terms, due to the increase in $\tau_{D}$ (that is stronger than the possible decrease of the l.h.s. due to second order effects on $\Gamma$ ). Such reduction occurs together with a reduction in the optimal $F_{P}$, given the convexity of the stand alone problem. When $F_{P}^{0}=0, F_{P}^{*}=0$ as well and both $\frac{\partial \Delta C}{\partial F_{P}}$ and $\frac{\partial \Delta T}{\partial F_{P}}$ are zero. A similar argument leads us to conclude that $F_{S}^{*} \geq F_{S}^{0}$, focusing on condition (iv). Theorem 2 proves that $F_{P}^{0}=0$ if $\tau_{P} \leq z$. It follows that $F_{P}^{*}=F_{P}^{0}=0$ when $\tau_{P} \leq z$.

Now we can prove that $\omega^{*}=0$ when $\tau_{D}>0$. Suppose to the contrary that $\omega^{*}>0$. Then, default costs and taxes in the parent as well as in the subsidiary are unchanged with respect to the $\omega^{*}=0$ case. However, intercorporate dividend taxes and, as a consequence, $\Delta T$, are positive, thereby reducing value. Hence, $\omega^{*}=0$ is the only feasible solution. 
(ii) Recall that, according to Theorem 2ii), $\tau_{P} \geq z^{\prime}$ implies positive optimal parent debt, $F_{P}^{0}>0$. Let us now consider an increase in $\tau_{D}$. It is possible that $F_{P}^{*}=0$. In such case, part (i) of the theorem applies and hence $\omega^{*}=0<1$. Otherwise, $F_{P}^{*}>0$. In such case, solutions with $\omega^{*}=1$ exist when condition (viii), evaluated at $\omega^{*}=1$, is satisfied. Such condition is

$$
-\frac{\partial \Delta C}{\partial \omega}\left(\tau_{D}, F_{P}^{*}, F_{S}^{*}\right)+\frac{\partial \Delta T}{\partial \omega}\left(\tau_{D}, F_{P}^{*}, F_{S}^{*}\right)=\mu_{3},
$$

with $\mu_{3} \leq 0$. Thus, $\omega^{*}<1$ if the l.h.s. of (B.13) is strictly positive. When $\tau_{D} \rightarrow 0$ the first term of the sum on the l.h.s. of the equation is negative and the second term disappears, whereas when $\tau_{D}=1$ the first term goes to zero, while the second term is positive. Being the 1.h.s. continuous and increasing in $\tau_{D}$, because of convexity, there exists a level of $\tau_{D}$, that we denote as $\underline{\tau}_{D}$ above which there is no solution at $\omega^{*}=1$.

We are now ready to prove Theorem 3. The condition for the existence of a pyramid descends directly from part ii) of the Lemma 2. A condition for the existence of horizontal groups is a condition on $\tau_{D}$ such that $\omega^{*}=0$ is the only feasible solution. $\omega^{*}=0$ implies $\mu_{4} \geq 0, \mu_{3}=0$ in (B.3). Condition (viii) in (B.3) when $\omega^{*} \rightarrow 0$ reads

$$
\begin{aligned}
& -\frac{\partial \Delta C}{\partial \omega}\left(\tau_{D}, F_{P}^{*}, F_{S}^{*}\right)+ \\
& +\phi \tau_{D} \int_{X_{S}^{d *}}^{+\infty}\left(x\left(1-\tau_{S}\right)+\tau_{S} X_{S}^{Z *}-F_{S}^{*}\right) f(x) d x=\mu_{4}
\end{aligned}
$$

where we considered that the upper limit of integration, $\frac{X_{P}^{d}}{\omega\left(1-\tau_{D}\right)\left(1-\tau_{S}\right)}+X_{S}^{d}$, tends to $+\infty$ when $\omega$ goes to 0 and we denoted with $X_{i}^{Z *}$ and $X_{i}^{d *}$ for $i=P, S$ the tax shield and default threshold, respectively, evaluated at the optimum. The l.h.s. of the above equation is nonpositive for $\tau_{D}=0$ and is increasing in $\tau_{D}$, since its first derivative with respect to $\tau_{D}$ is strictly positive. It follows that a necessary condition for the existence of a solution where $\omega^{*}=0$, for given $F_{S}^{*}$ and $F_{P}^{*}$, is that $\tau_{D}$ is higher than a certain level, which we define as $\bar{\tau}_{D}$ that solves

$$
-\frac{\partial \Delta C}{\partial \omega}\left(\tau_{D}, F_{P}^{*}, F_{S}^{*}\right)+\phi \tau_{D} \int_{X_{S}^{d *}}^{+\infty}\left(x\left(1-\tau_{S}\right)+\tau_{S} X_{S}^{Z *}-F_{S}^{*}\right) f(x) d x=0
$$

Also, recall that the 1.h.s. of the Kuhn Tucker condition (viii) is increasing in $\omega$. Hence, 
for every $\tau_{D}>\bar{\tau}_{D}, \omega^{*}=0$ is the only feasible solution, because $\omega^{*}>0$ would contradict condition (viii) that requires the l.h.s. to be lower than or equal to zero. Also, notice that convexity of the objective function in $\omega$ implies also that $\underline{\tau}_{D} \leq \bar{\tau}_{D}$. Finally, value and default costs neutrality under the conditions of the theorem follow directly from Lemma 2 part i).

Proof of Theorem 4

(i) A cap on subsidiary debt introduces a new constraint in the optimization program: $F_{S}^{* *} \leq K$, where $K$ is the imposed cap and $\left(F_{P}^{* *}, F_{S}^{* *}, \omega^{* *}\right)$ denotes the solution to such a constrained program. We thus consider the set of Kuhn-Tucker conditions in (B.3) and modify them appropriately:

$$
\begin{array}{ll}
(i v)^{\prime}: & \frac{\partial T_{S A}^{S}\left(F_{S}^{* *}\right)}{\partial F_{S}}+\frac{\partial C_{S A}^{S}\left(F_{S}^{* *}\right)}{\partial F_{S}}-\frac{\partial \Gamma\left(F_{P}^{* *}, F_{S}^{* *}\right)}{\partial F_{S}}-\frac{\partial \Delta C\left(F_{P}^{* *}, F_{S}^{* *}\right)}{\partial F_{S}}+\frac{\partial \Delta T\left(F_{P}^{* *}, F_{S}^{* *}\right)}{\partial F_{S}}=\mu_{2}-\mu_{3}, \\
(v i i)^{\prime}: & \mu_{1} \geq 0, \mu_{2} \geq 0, \mu_{3} \geq 0 \\
(x i v)^{\prime}: & \mu_{3}\left(F_{S}^{* *}-K\right)=0 .
\end{array}
$$

Let us consider the case in which the new constraint (xiv)' is binding, so that $F_{S}^{* *}=K$, and inspect the conditions ensuring zero parent debt. Hence, $\mu_{1} \geq 0, \mu_{2}=0, \mu_{3} \geq 0$. We focus on condition (i), and we refer the reader to the proof of Theorem 2 for the discussion of other conditions. Condition (i), when $F_{P}^{* *}=0$ and $F_{S}^{* *}=K$, becomes:

$$
\begin{aligned}
& -\tau_{P}(1-G(0)) \frac{\partial X_{P}^{Z}(0, K)}{\partial F_{P}}-\frac{\partial X_{S}^{Z}(0, K)}{\partial F_{P}} \int_{X_{S}^{d}(0, K)}^{+\infty} \tau_{S} f(x) d x+ \\
& +\alpha_{S} \phi \frac{\partial X_{P}^{d}(0, K)}{\partial F_{P}}\left[\int_{0}^{X_{S}^{Z}(0, K)} x g\left(x, \frac{K}{1-\tau}-\frac{x}{1-\tau}\right) d x+\right. \\
& \left.+\int_{X_{S}^{Z}(0, K)}^{X_{S}^{d}(0, K)} x g\left(x, X_{S}^{d}(0, K)-x\right) d x\right]=\mu_{1}
\end{aligned}
$$

The first term on the l.h.s. is negative, the second is negative as well and increasing in $\mathrm{K}$ (as $X_{S}^{Z}$ is increasing and convex in $F_{P}$ ), while the third one is null when $K=0$ and is increasing in $K$. It follows that condition (i) can be satisfied only for a $K$ high enough. Because a negative l.h.s. of equation (B.16) implies positive optimal parent leverage, a zero leverage parent is possible only if $K>\bar{K}$, with $\bar{K}$ solving the following equation and being the cap 
above which the parent has zero optimal leverage:

$$
\begin{aligned}
& \alpha_{S} \phi \frac{\partial X_{P}^{d}(0, \bar{K})}{\partial F_{P}}\left[\int_{0}^{X_{S}^{Z}(0, \bar{K})} x g\left(x, \frac{\bar{K}}{1-\tau_{S}}-\frac{x}{1-\tau_{S}}\right) d x+\right. \\
+ & \left.\int_{X_{S}^{Z}(0, \bar{K})}^{X_{S}^{d}(0, \bar{K})} x g\left(x, X_{S}^{d}(0, \bar{K})-x\right) d x\right]+ \\
- & \frac{\partial X_{S}^{Z}(0, \bar{K})}{\partial F_{P}} \int_{X_{S}^{d}(0, \bar{K})}^{+\infty} \tau_{S} f(x) d x \\
= & \mu_{1}+\tau_{P}(1-G(0)) \frac{\partial X_{P}^{Z}(0, \bar{K})}{\partial F_{P}} .
\end{aligned}
$$

Hence, for every $K<\bar{K}$ the parent has optimal positive leverage. Notice that the higher $\alpha_{S}$, the lower the required cap level $\bar{K}$ that allows for the presence of a zero leverage optimal parent company, while, on the contrary, the higher $\tau_{P}$, the higher the required cap, because the marginal gain from raising debt in the parent is higher. Considerations similar to the unconstrained case apply to condition (iv)', which is met at $F_{S}^{* *}=K$ by an appropriate choice of $\mu_{3}$. This concludes our proof of part (i).

(ii) The proof follows directly from Theorem 2 part ii), whose proof relies on the parent having positive leverage.

(iii) We discuss the first Kuhn-Tucker condition when $F_{P}=F_{S A}^{P *}, F_{S}=F_{S}^{* *}=K$, assuming $\tau_{D}<\underline{\tau}_{D}$. In this case, the only feasible solution implies $\omega^{*}=1$. Then, given our convexity assumption, we can find a sufficient condition for $F_{P}^{* *}>F_{S A}^{P *}$ :

$$
\left.\left(-\frac{\partial \Gamma}{\partial F_{P}}-\frac{\partial \Delta C}{\partial F_{P}}+\frac{\partial \Delta T}{\partial F_{P}}\right)\right|_{F_{P}=F_{S A}^{P *}, F_{S}=F_{S}^{* *}, \omega^{*}=1}<0 .
$$

This implies $\frac{\alpha_{P}}{\alpha_{S}}>C$, where $\mathrm{C}$ is equal to

$$
\frac{\left.\frac{\partial X_{P}^{d}}{\partial F_{P}}\left[\int_{0}^{X_{S}^{Z}(K)} x g\left(x, X_{S A}^{P, d *}+\frac{K}{1-\tau_{P}}-\frac{x}{1-\tau_{P}}\right) d x+\int_{X_{S}^{Z}(K)}^{X_{X}^{d}(K)} x g\left(x, X_{S A}^{P, d *}+X_{S}^{d}(K)-x\right) d x\right)\right]}{\frac{\frac{\partial \Delta C}{\partial F_{P}}}{\alpha_{P}}}
$$

where all the derivatives involved are evaluated at $\left(F_{S A}^{P *}, K\right)$. 


\section{Proof of Theorem 5}

We know from Luciano and Nicodano (2014) that conditional guarantees are value increasing. As a consequence, the value of the group structure, when there is a bailout guarantee and subsidiary debt is set equal to the optimal stand alone level, is $\nu_{P S}\left(F_{P}^{* *}, F_{S A}^{S *}\right) \geq$ $\nu_{S A}\left(F_{S A}^{P *}, F_{S A}^{S *}\right)$, where $\nu_{S A}\left(F_{S A}^{S *}, F_{S A}^{P *}\right)=\nu_{P S}\left(F_{S A}^{P *}, F_{S A}^{S *}, \Gamma=0, \omega=0\right)$. We know, from the previous considerations, that the f.o.c. for a solution with $F_{P}^{* *}>0$ include:

$$
\frac{\partial T_{S A}^{P}\left(F_{P}^{* *}\right)}{\partial F_{P}}+\frac{\partial C_{S A}^{P}\left(F_{P}^{* *}\right)}{\partial F_{P}}-\frac{\partial \Gamma\left(F_{P}^{* *}, F_{S A}^{S *}\right)}{\partial F_{P}}-\frac{\partial \Delta C\left(F_{P}^{* *}, F_{S A}^{S *}\right)}{\partial F_{P}}+\frac{\partial \Delta T\left(F_{P}^{* *}, F_{S A}^{S *}\right)}{\partial F_{P}}=0 .
$$

The equivalent condition in the stand alone case is:

$$
\frac{\partial T_{S A}^{P}\left(F_{S A}^{P *}\right)}{\partial F_{S A}}+\frac{\partial C_{S A}^{P}\left(F_{S A}^{P *}\right)}{\partial F_{S A}}=0 .
$$

We also know that $\frac{\partial \Gamma\left(F_{P}^{* *}, F_{S A}^{P *}\right)}{\partial F_{P}} \leq 0$, since the guarantee is non-zero and more valuable the lower is $F_{P}$. Also, when $\tau_{D}>\bar{\tau}_{D}, \Delta C=0$ and $\Delta T=0$ for all $F_{P}$ and $F_{S}$ since $\omega^{*}=0$. Since by assumption $T_{S A}^{P}+C_{S A}^{P}$ is convex in the face value of debt, it follows that $F_{P}^{* *}<F_{S A}^{P *}$. As a consequence, it follows that the default costs of the group are lower than the ones of two stand-alone units. Indeed:

$$
\begin{array}{r}
C_{P}\left(F_{P}^{* *}\right)+C_{S}\left(F_{S}^{* *}\right)=C_{S A}^{P}\left(F_{P}^{* *}\right)+C_{S A}\left(F_{S}^{* *}\right)-\Gamma\left(F_{P}^{* *}, F_{S A}^{* *}\right)-\Delta C\left(F_{P}^{* *}, F_{S A}^{* *}\right)= \\
=C_{S A}^{P}\left(F_{P}^{* *}\right)+C_{S A}\left(F_{S A}^{S *}\right)-\Gamma\left(F_{P}^{* *}, F_{S A}^{S *}\right)<C_{S A}^{P}\left(F_{P}^{* *}\right)+C_{S A}\left(F_{S A}^{S *}\right)<C_{S A}^{P}\left(F_{S A}^{P *}\right)+C_{S A}\left(F_{S A}^{S *}\right) .
\end{array}
$$

The last two inequalities hold because $\Gamma(\cdot, \cdot)$ is positive, as soon as $F_{P}^{* *}>0$ and because stand alone default costs are increasing in the face value of debt, respectively.

\section{Acknowledgements}

The authors thank an anonymous referee for very sharp comments, Michela Altieri, Bruno Biais, Nicola Branzoli, Marco Da Rin, Jon Danielsson, Gerardo Ferrara, Paolo Fulghieri, Ulrich Hege, Florian Heider, Giulia Iori, Saqib Jafarey, Elisa Luciano, Arie Melnik, Mario

Pascoa, Roberto Marfè, Sergey Stepanov, Marti Subrahmanyam, Silvia Tiezzi, Guillaume Vuillemey and Klaus Zauner for useful suggestions, together with seminar participants at 
the Bank of Italy, Cass Business School, City University London, the ESSFM at Gerzensee, the FMG at LSE, the Universities of Surrey, Tilburg, Siena, Modena and Reggio Emilia, the 2016 International Moscow Finance Conference, the 2016 Workshop on Money Banking and Finance, the 2015 GRETA Conference, the IRMC 2014 and 2013 SIE Meetings, the 13th LAGV Conferences, the XXIII International Conference on Money, Banking and Finance, the XIV Workshop in Quantitative Finance. Luca Regis gratefully acknowledges financial support from the Crisis Lab project funded by the Italian Ministry of Education. 


\section{References}

Acharya, V., Hahn, M., Kehoe, C., 2013. Corporate governance and value creation: evidence from private equity. Review of Financial Studies 26, 368-402.

Almeida, H., Wolfenzon, D., 2006. A theory of pyramidal ownership and family business groups. Journal of Finance 61, 2637-2680.

Almeida, H., Park, H., M. Subrahmanyam, Wolfenzon D., 2011. The structure and formation of Korean chaboels. Journal of Financial Economics 99, 447-475.

Altomonte, C., Rungi A., 2013. Business groups as hierarchies of firms. ECB Working Paper 1554 .

Axelson, U., Stromberg, P., Weisbach, M.S., 2009. Why are buyouts levered? The financial structure of private equity funds. Journal of Finance 64, 1549-82.

Barclay, M., Holderness, C., Sheehan, D., 2009. Dividends and corporate shareholders. Review of Financial Studies 22, 2423-2455.

Bernanke B., Campbell J., Whited, T., 1990. U.S. corporate leverage: developments in 1987 and 1988. Brookings Papers on Economic Activity 1, 255-278.

Bianco M., Nicodano, G., 2006. Pyramidal groups and debt. European Economic Review $50,937-961$.

Bloch, L., Kremp, E., 1999. Ownership and voting power in France. Working Paper Fondazione Enrico Mattei 62.

Blouin, J., Huizinga, H., Laeven, L., Nicodème, G., 2014. Thin capitalization rules and multinational firm capital structure. IMF Staff Working Papers 14/12. 
Bodie, Z., Merton, R., 1992. On the management of financial guarantees. Financial Management 21, 87-109.

Boot, A., Greenbaum, S., Thakor, A., 1993. Reputation and discretion in financial contracting. American Economic Review 83, 1165-1183.

Brok, P., 2016. International tax spillovers and capital structure. Mimeo, Tilburg University.

Cestone, G., Fumagalli, C., Kramarz, F., Pica, G., 2017. Insurance between firms: the role of internal labor markets, IGIER Working Paper 528.

Chemmanur, T. J., John, K., 1996. Optimal incorporation, structure of debt contracts, and limited-recourse project financing. Journal of Financial Intermediation 5, 372-408.

Chetty, R., Saez, E., 2010. Dividend and corporate taxation in an agency model of the firm. American Economic Journal: Economic Policy 2, 1-31.

Cooper, M., McClelland, J., Pearce J., Prisinzano, R., Sullivan, J., Danny, Y., Zidar, O., Zwick, E., 2015. Business in the United States: who owns it and how much tax do they pay?. NBER Working Paper 21651.

Dahlquist, M., Robertson, G., Rydquist, K., 2014. Direct evidence of dividend tax clienteles. Journal of Empirical Finance 28, 1-12.

De Angelo, H., Masulis, R., 1980. Optimal capital structure under corporate and personal taxes. Journal of Financial Economics 8, 3-29. 
De Jong, A., DeJong, D., Hege, U., Mertens, G., 2012. Blockholders and leverage: when debt leads to higher dividends. Working Paper, Rotterdam School of Management.

De Marzo P., Duffie, D., 1999. A liquidity based model of security design. Econometrica $67,65-99$.

Demsetz, H., Lehn, K., 1985. The structure of corporate ownership: causes and consequences. Journal of Political Economy 93, 1155-77.

Desai, M., Foley, F. Hines, J., 2004. A multinational perspective on capital structure choice and internal capital markets. Journal of Finance 59, 2451-87.

Faccio, M., Lang, H., 2002. The ultimate ownership of Western European corporations. Journal of Financial Economics 65, 365-395.

Faulkender, Michael W., Smith, J. M., 2014. Taxes and leverage at multinational corporations. Journal of Financial Economics 122, 120.

Gorton, G., Souleles, N., 2006. Special purpose vehicles and securitization. In: Stulz, R., Carey, M. (Eds.), The Risks of Financial Institutions. University of Chicago Press, Chicago, IL.

Fulghieri, P., Sevilir, M., 2011. Mergers, spinoffs, and employee incentives. Review of Financial Studies 24, 2207-2241.

Graham J.R., Tucker, A.L., 2006. Tax shelters and corporate debt policy. Journal of Financial Economics 81, 563-594.

Guo, S., Hotchkiss, E., Song, W., 2011. Do buyouts (still) create value? Journal of Finance 66, 479517. 
Han, J., K. Park, Pennacchi, G., 2015. Corporate taxes and securitization. Journal of Finance 70, 1287-1321.

Her Majesty's Revenue and Customs, INTM541010 - Introduction to thin capitalisation (legislation and principles), http://www.hmrc.gov.uk.

Herring, R., Carmassi, J., 2009. The corporate structure of international financial conglomerates. In: A. Berger,P. Molyneux, and J.Wilson (eds.), The Oxford Handbook of Banking. Oxford: Oxford University Press.

Huizinga, H., Laeven, L., Nicodème, G., 2008. Capital structure and international debt shifting. Journal of Financial Economics 88, 80-118.

Kandel, E., Kosenko, K., Morck, R., Yafeh, Y., 2015. The great pyramids of America: a revised history of U.S. business groups, corporate ownership and regulation, 1930-1950. ECGI Finance Working Paper 449.

Kaplan, S., 1989. Management buyouts: evidence on taxes as a source of value. Journal of Finance 44, 611-632.

Kim, W., Lin, Y., Sung, T., 2007. Group control motive as a determinant of ownership structure in business conglomerates. Pacific-Basin Finance Journal 15, 213-252.

Kolasisnski, A., 2009. Subsidiary debt, capital structure and internal capital markets. Journal of Financial Economics 94, 327-343.

Leland, H., 2007. Purely financial synergies and the optimal scope of the firm: implications for mergers, spin offs, and structured finance. Journal of Finance 62, 765-807. 
Lewellen, K., Robinson, L., 2013. Internal ownership structures of U.S. multinational firms, Working Paper, available at ssrn.com.

Luciano, E., Nicodano, G., 2014. Guarantees, leverage, and taxes. Review of Financial Studies 27, 2736-2772.

Masulis, R., Pham, P. and Zein, J., 2011. Family business groups around the world: financing advantages, control motivations and organizational choices. Review of Financial Studies 24, 3556-3600.

Matvos, G. , Seru, A., 2014. Resource allocation within firms and financial market dislocation: evidence from diversified conglomerates. Review of Financial Studies 27, 1143-1189.

Morck R., 2005. How to eliminate pyramidal business groups - the double taxation of intercorporate dividends and other incisive uses of tax policy. In: J. Poterba (ed.), Tax Policy and the Economy 19, 135-179.

Naidech, S.W., 2011. Private equity fund formation, practice note. Practical Law Publishing Limited and Practical Law Company, Inc: http://us.practicallaw.com/3-509-1324.

Peaslee J.M., Nirenberg, D.Z., 2001. Federal income taxation of securitization transactions, Frank J. Fabozzi Associates.

Penati, A., Zingales, L., 1997. Efficiency and distribution in financial restructuring. CRSP Working Paper n. 466, www.ssrn.com

OECD, 2016. Limiting base erosion involving interest deductions and other financial payments. Action 4 - 2016 update inclusive framework on BEPS. OECD Publishing. 
Segura, A., 2017. Why did sponsor banks rescue their SIVs? A signaling model of rescue. Review of Finance, forthcoming.

Stein, J., 1997. Internal capital markets and the competition for corporate resources. Journal of Finance 52, 111-133.

Strebulaev, I.A., and Yang, B., 2013. The mystery of zero-leverage firms. Journal of Financial Economics 109, 1-23.

Villalonga, Amit, B., 2009. How are U.S. family firms controlled? Review of Financial Studies 22, 3047-3091.

Zingales, L., 1995. Insider ownership and the decision to go public. Review of Economic Studies 62, 425-448. 